\title{
Nanoreinforcements of Two-Dimensional Nanomaterials for Flame Retardant Polymeric Composites: An Overview
}

\author{
Shaolin Lu, Wei Hong $\mathbb{D}^{\mathrm{D}}$, and Xudong Chen \\ Key Laboratory for Polymeric Composite and Functional Materials of Ministry of Education, School of Chemistry, \\ Sun Yat-sen University, Guangzhou 510275, China \\ Correspondence should be addressed to Wei Hong; hongwei9@mail.sysu.edu.cn
}

Received 19 June 2019; Revised 13 August 2019; Accepted 17 August 2019; Published 4 December 2019

Academic Editor: Gyorgy Szekely

Copyright (c) 2019 Shaolin Lu et al. This is an open access article distributed under the Creative Commons Attribution License, which permits unrestricted use, distribution, and reproduction in any medium, provided the original work is properly cited.

\begin{abstract}
Polymer materials are ubiquitous in daily life. While polymers are often convenient and helpful, their properties often obscure the fire hazards they may pose. Therefore, it is of great significance in terms of safety to study the flame retardant properties of polymers while still maintaining their optimal performance. Current literature shows that although traditional flame retardants can satisfy the requirements of polymer flame retardancy, due to increases in product requirements in industry, including requirements for durability, mechanical properties, and environmental friendliness, it is imperative to develop a new generation of flame retardants. In recent years, the preparation of modified two-dimensional nanomaterials as flame retardants has attracted wide attention in the field. Due to their unique layered structures, two-dimensional nanomaterials can generally improve the mechanical properties of polymers via uniform dispersion, and they can form effective physical barriers in a matrix to improve the thermal stability of polymers. For polymer applications in specialized fields, different two-dimensional nanomaterials have potential conductivity, high thermal conductivity, catalytic activity, and antiultraviolet abilities, which can meet the flame retardant requirements of polymers and allow their use in specific applications. In this review, the current research status of two-dimensional nanomaterials as flame retardants is discussed, as well as a mechanism of how they can be applied for reducing the flammability of polymers.
\end{abstract}

\section{Introduction}

Polymer materials, due to the continuous development of science and technology, have been widely used in all aspects of humankind's basic life necessities [1]. Due to the environmental adaptability of polymer materials, they have been widely used in construction, transportation, agriculture, electronics and electrical systems, textile, and other major economic areas. However, most of polymer materials are highly flammable, with fast combustion propagation rates and are not easily extinguished. A large portion of annual fires worldwide are related to polymer materials. According to statistics, 237,000 fires were reported in China in 2018, resulting in 1407 deaths, 798 injuries, and direct property losses amounting to 3.675 billion RMB [2]. Therefore, it is critical to research and develop effective flame retardants so as to reduce the risks of accidental fires, costly damage to buildings materials, and to widespread health and safety [3].

Polymer flame retardants are mainly divided into halogen and halogen-free categories. However, halogen flame retardants have limited use because they release toxic gases and corrosive smoke during combustion. Therefore, halogen-free compounds are currently being considered as promising flame retardants, based on their more environmentally friendly properties [4]. Numerous efforts have been made to find suitable halogen-free flame retardants polymers. Traditional inorganic flame retardants, including aluminium hydroxide $[5,6]$ and ammonium polyphosphate $[7,8]$, are usually added to polymers in large quantities, which can often lead to a decline in the processability and mechanical properties of these doped materials. Organic phosphorus flame retardants $[9,10]$ have high flame retardant efficiency, but most of these are liquids with poor heat resistance. In recent years, in addition to graphene, two-dimensional nanomaterials, such as hexagonal boron nitride (h-BN) [11-16], molybdenum disulfide $\left(\mathrm{MoS}_{2}\right)$ [17-20] and black phosphorus [21] (Figure 1 ), have also been developed, which has greatly expanded the properties and applications of two-dimensional materials in this realm. Notably, two-dimensional materials and their derivatives have been extensively studied as photocatalysts 


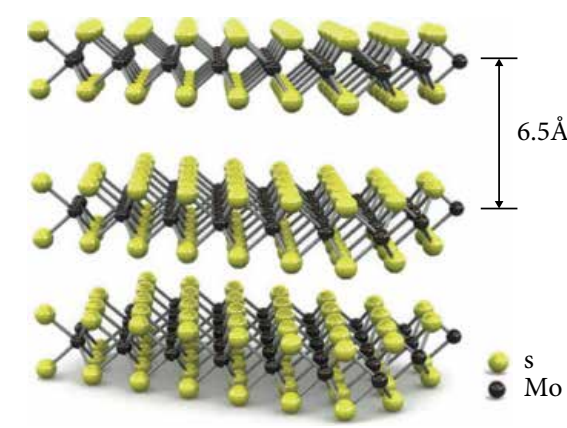

(a)

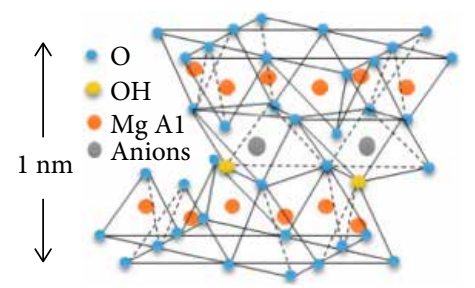

(d)

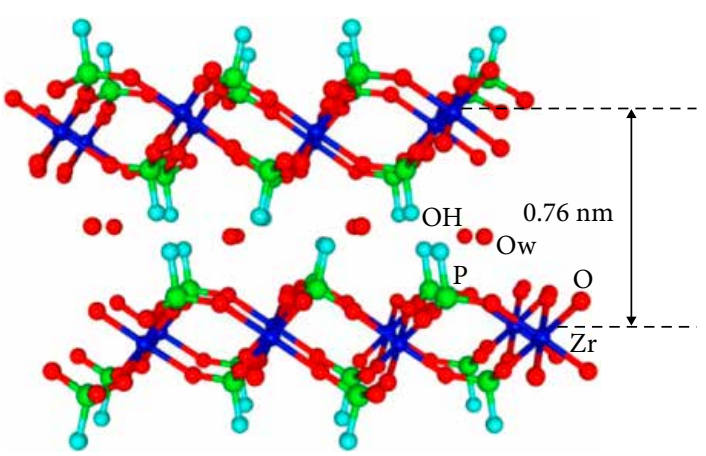

(b)

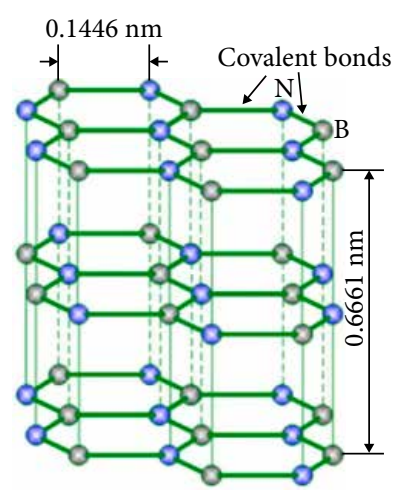

(c)

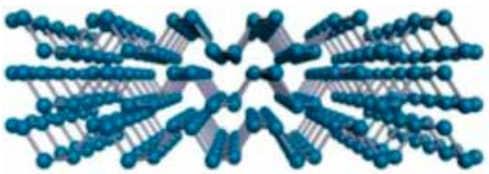

(e)

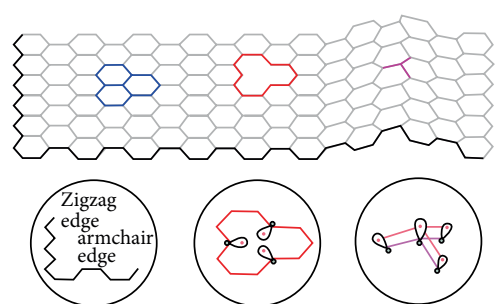

(I)

(II)

(f)

FIGURE 1: Structure of some two-dimensional nanomaterials. (a) Molybdenum disulfide [52]. (b) $\alpha$-zirconium phosphate [53]. (c) Hexagonal boron nitride [54]. (d) Layered double hydroxide [55]. (e) Black phosphorus [56]. (f) Graphene with (I) Zigzag and armchair edges, (II) Monovacancy, (III) Local structure of a curved graphene sheet [57].

[22, 23], sensors [24], drug delivery vehicles [25], transistors [26], lithium ion batteries [27], water treatment agents [28], ion exchange [29], fuel cells [30], nanofiltration membranes [31], conductive inks [32], quantum dots [33], adsorbents [34] and supercapacitors [35]. Moreover, two-dimensional nanomaterials/polymer composites have also been investigated. Lin et al. [36] realized the intercalation of polythiophene into $\mathrm{MoS}_{2}$ could be achieved by means of in situ polymerization of intercalated monomers. This method has contributed to enhancing the conductivity of composites at ambient temperature. Wang et al. [37] prepared a high-performance thermal interface material based on exfoliated boron nitride nanosheets (BNNSs) and polystyrene (PS) microspheres. Yan et al. [38] reported that $\mathrm{g}-\mathrm{C}_{3} \mathrm{~N}_{4}$-poly(3-hexylthiophene) polymer composites achieve enhanced hydrogen production using water as a substrate under visible light. Particularly, two-dimensional nanomaterials have attracted extensive attention in the field of flame retardant and smoke suppression due to their unique structure and properties [39].

Compared with zero-dimensional nanomaterials and one-dimensional nanomaterials, two-dimensional nanomaterials have emerged as a superior flame retardant option due to their layered structures, which have high thermal stability and can form a physical barrier in a polymer matrix $[17,40]$. Additionally, homogeneous dispersion of a small amount of two-dimensional nanomaterials in polymers can effectively improve the mechanical properties of polymers [41, 42]. A well-dispersed layered structure in a polymer can not only greatly improve the thermal stability of a polymer $[43,44]$ but it can also further enhance the action of char residual in the inhibition of heat and mass transfer $[39,45]$. It is believed that the biggest obstacle to the application of two-dimensional nanomaterials as flame retardant additives is the high cost and the low yield of the peeled sheet structures [46]. Recently, as the number of publications related to these emerging twodimensional nanomaterials has increased dramatically, a large number of studies on the large-scale production of twodimensional nanosheets have paved the way for flame-retardant applications [47, 48]. Yao et al. [49] reported a facile and scalable method for the preparation of monolayer and fewlayer of $\mathrm{BN}, \mathrm{MoS}_{2}$, and graphene using a combination of low-energy ball milling and sonication. These prepared 2D nanosheets could be well dispersed in high concentrations of aqueous solutions as $1.2 \mathrm{mg} / \mathrm{ml}$ (for BN), $0.8 \mathrm{mg} / \mathrm{ml}$ (for $\mathrm{Mos}_{2}$ ) and $0.9 \mathrm{mg} / \mathrm{ml}$ (for graphene). These advantages make it possible to apply high performance $2 \mathrm{D}$ nanomaterials/polymers at low cost with great potential, which is beneficial to the application of such new 2D nanomaterials in the flame retardant field. If suitable two-dimensional nanomaterials are selected for the application of specific polymers and the functionally controllable two-dimensional nano flame retardants associated are prepared via a simple and versatile method, the multi-functional application challenges of polymers can be overcome. It is well known that nano-fillers can easily achieve good flame retardant effects (below $6 \mathrm{wt} \%$ ) at low load, meaning that they have potential industrial prospects $[50,51]$.

Recent progress and future development trends in flame-retardant materials using two-dimensional materials were summarized above. This also highlighted the effects of two-dimensional nanomaterials and the unique flame retardant mechanisms of sulfur, phosphorus, nitrogen, silicon, layered double hydroxide, and carbon skeleton. 


\section{The Flame-Retardant Mechanism of Two-Dimensional Nanomaterials}

The combustion of polymer materials involves the evolution of combustible volatiles through decomposition in an oxygen-rich atmosphere. No matter which flame retardant is used, its flame-retardant mechanism is through one of the following two processes (or occasionally a combination of the two): (i) condensed phase or (ii) gas phase [58]. Figure 2 shows three possible processes of flame retardant mechanisms.

\subsection{Condensed-Phase Mechanism}

2.1.1. Physical Barrier. Two-dimensional nano-layered flame retardants can function as an effective insulating barrier, to inhibit mass loss during the thermal degradation process.

Shi et al. [61] reported a ternary PS/g- $\mathrm{C}_{3} \mathrm{~N}_{4} / \mathrm{aMWCNT}$ assembled system using LBL technology, which led to the improved thermal stability of the PS matrix, including $T_{-10 \%}$, $T_{-\max }$, and char residue increased by $11^{\circ} \mathrm{C}, 20.0^{\circ} \mathrm{C}$ and $6.5 \%$, respectively. The generation of total gaseous products was also distinctly inhibited by the ternary assembled systems. Moreover, the ternary assembled systems showed outstanding improvements in flame retardancy; i.e., HRR and THR decreased by around $45 \%$ and $47 \%$, respectively. These enhancements were attributed to the LBL assembly strategy being conducive to building extremely tight barriers.

Hu et al. [62] synthesized a functionalized graphene oxide (FGO) that was grafted by hyper-branching as a flame retardant to reduce the combustion and toxicity of PS. The addition of $0.1 \%$ FGO significantly increased the $\mathrm{T}_{-5 \%}$ of PS-FGO0.1 nanocomposites compared to that of pure PS. This effect was attributed to the combined effect of the physical barrier and the capture of oxygen molecules and free radicals by FGO layers under atmospheric air. This enhanced barrier effect was also demonstrated by a suppressed mass loss rate, implying the retardation of mass transfer from nanocomposites to the flame zone.

2.1.2. Formation of a Continuous Char Layer. During the combustion process, a compact and stable char layer is formed on the surface of a polymer, which acts as a thermal insulating barrier to heat and separates oxygen from burning materials, thus preventing mass and heat transfer, reducing the heat release rate and total amount of flammable volatile gases after the char layer is established.

Xie et al. [63] synthesized a ZrP-decorated macromolecular charring agent (ZrP-d-MCA), which was then introduced into polypropylene. A mechanistic study showed that $\mathrm{ZrP}-\mathrm{d}$ MCA/APP effectively involved PP incorporation into the charring reaction, forming a compact and firm intumescent char layer with outstanding barrier properties. ZrP first catalyzed the carbonization of MCA on its surface, forming closed micro-nano char-cages, which then trapped the degradation products of $\mathrm{PP}$ and further catalyzed them into a thermostable graphitized char.

Feng et al. [64] proposed a ternary thermal interface material based on epoxy resin (EP), silver nanowires (AgNWs), and a small amount of flame-retardant functionalized graphene (GP-DOPO). Char analysis confirmed that the char's yield and quality (integrality and compact degree) were increased dramatically by incorporating GP-DOPO into EP/ AgNWs, due to the strong catalytic charring effect. The increased organic chars not only protected the AgNWs from melting and wicking action but also connected the AgNWs network to form a protective char layer with a compact and robust structure, which acted as a barrier to prevent the transfer of heat, oxygen, and flammable volatile products between the inside and outside of the polymer melt, thus improving the flame retardancy of the EP/AgNWs/GP-DOPO composite.

\subsection{Gas-Phase Mechanism}

2.2.1. Dilution of Oxygen by Inert Gases. The gas dilution flame retardant mechanism is typified by a large amount of nonflammable gases being produced during the decomposition process of a flame retardant at high temperatures, and these nonflammable gases can prevent the combustion of a polymer by diluting the oxygen concentration.

Wang et al. [65] reported Cardanol-BS modified layered double hydroxide (M-LDH) being synthesized by a coprecipitation method, and its subsequent incorporation into EP at different loadings. The degradation gaseous products could be mainly divided into two categories: one was inflammable gases, such as water vapor and $\mathrm{CO}_{2}$, and the other was flammable gases, such as carbonyl, aromatic compounds, and esters. The maximum absorbance intensity of inflammable volatiles for $\mathrm{EP} / \mathrm{LDH}-6 \%$ and $\mathrm{EP} / \mathrm{m}-\mathrm{LDH}-6 \%$ composites was much higher than that for pure EP, which effectively diluted the concentration of flammable volatiles.

$\mathrm{Xu}$ et al. [66] reported a hybrid RGO-LDH/Mo system through RGO-LDH modified by heptaheptamolybdate $\left(\mathrm{Mo}_{7} \mathrm{O}_{24}{ }^{6-}\right)$ via ion exchange method, and introduced it into polyurethane elastomer (PUE). Compared with pristine PUE, the PHRR of PUE1 was decreased by $36.4 \%$ because the LDH layer and carbon residue inhibited the volatilization of combustible gases produced during polymer decomposition, isolated oxygen, and reduced the thermal radiation of materials. At the same time, due to the generated water vapor, the temperature was lowered and the combustion process of the composites was delayed, so the heat was absorbed in the endothermic decomposition process of $\mathrm{LDH}$.

2.2.2. Gas Phase Free Radical Inhibition. Flame retardants can also capture and annihilate active free radicals, thus preventing and inhibiting free radical chain reactions, reducing the flame burning rate and extinguishing a flame.

Yang et al. [67] used organophilic $\alpha$-zirconium phosphate $(\alpha$-ZRP, OZRP) as a synergistic agent with aluminium hydroxide $(\mathrm{ATH})$, and introduced it into low-density polyethylene and ethylene-vinyl acetate (LDPE/EVA) blends. As LDPE/ EVA/(ATH, OZrP) hybrids burned, ATH first decomposed rapidly with the release of hydration water. This endothermic decomposition lowers the temperature of the reaction, and the released water vapor dilutes flammable volatile gasses. Second, a small amount of phosphorus monoxide (PO•) produced by the combustion of OZrP can quench active radicals produced by the burning of the gas phase, while the exfoliated $\mathrm{OZrP}$ layers can efficiently promote the formation of compact 

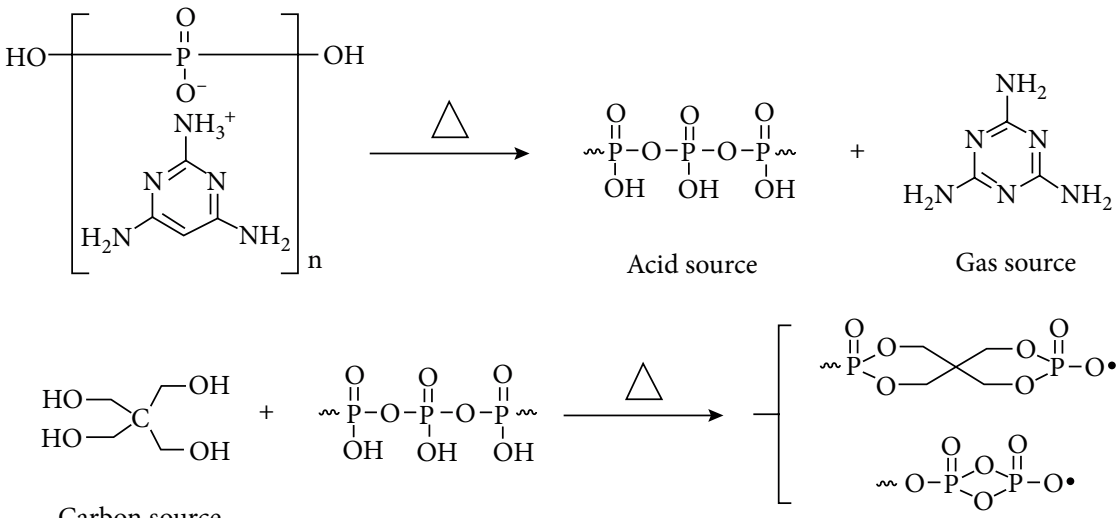

Carbon source
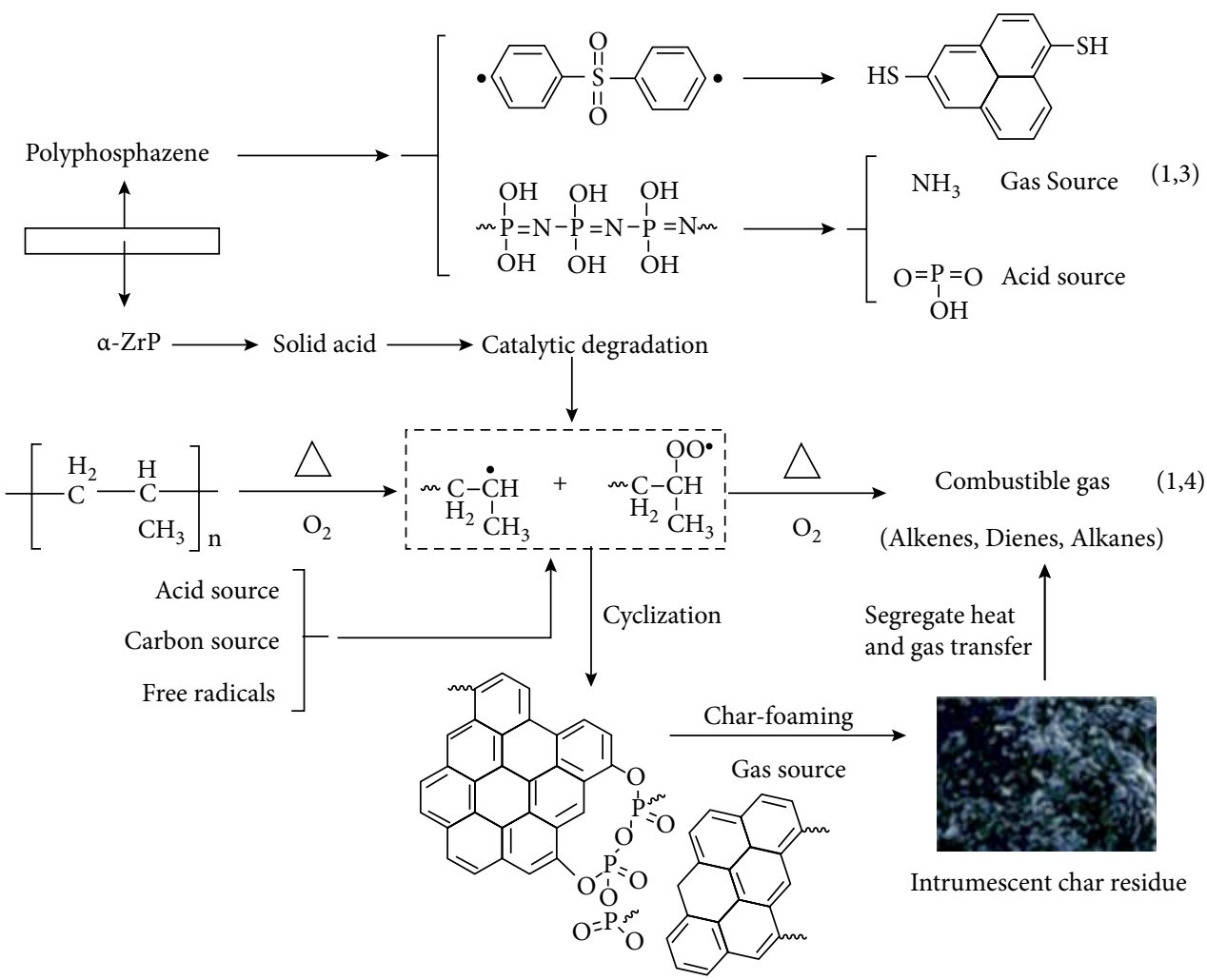

Precursor of intrumescent char

(a)

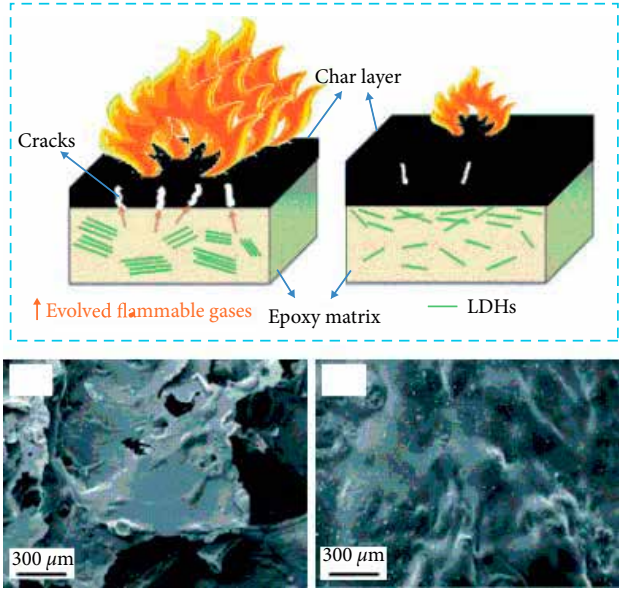

(b)
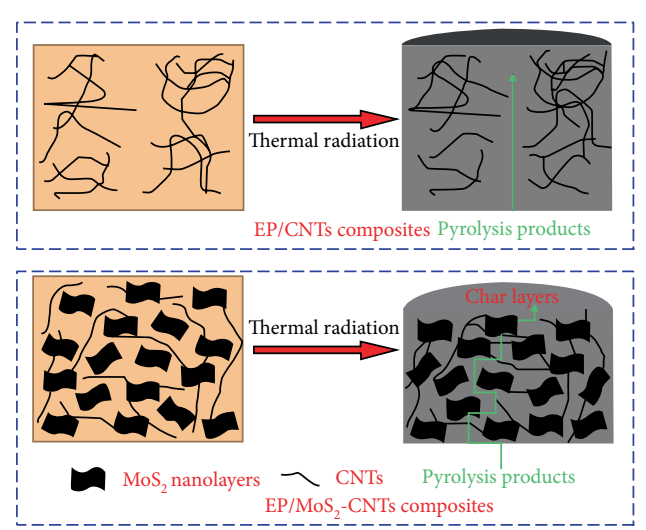

(c)

FIGURE 2: Flame retardant mechanisms of partial two-dimensional materials. (a) The free radicals of PP chain scission are inhibited, and then a coherent, thermally stable, and tough swollen char is formed under the catalysis of solid acid sites on the surface of a-zrp core [59]. (b) LDHs catalyze the formation of a thick char layer on the surface of EP [60]. (c) A MoS - CNT hybrid acts as a physical barrier in an EP [19]. 

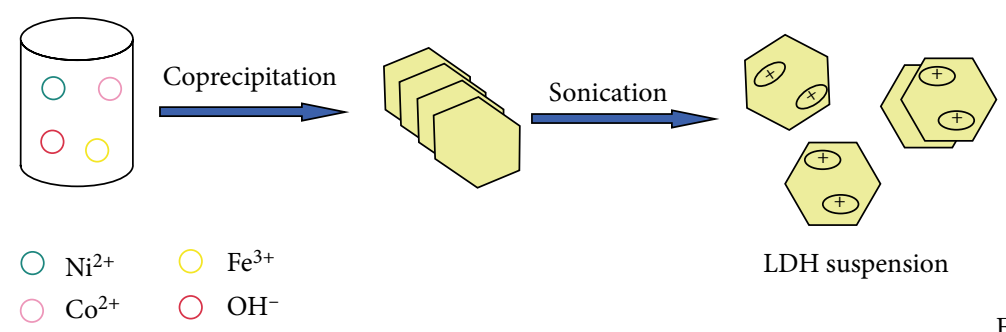

$\mathrm{Co}^{2+} \bigcirc \mathrm{OH}^{-}$
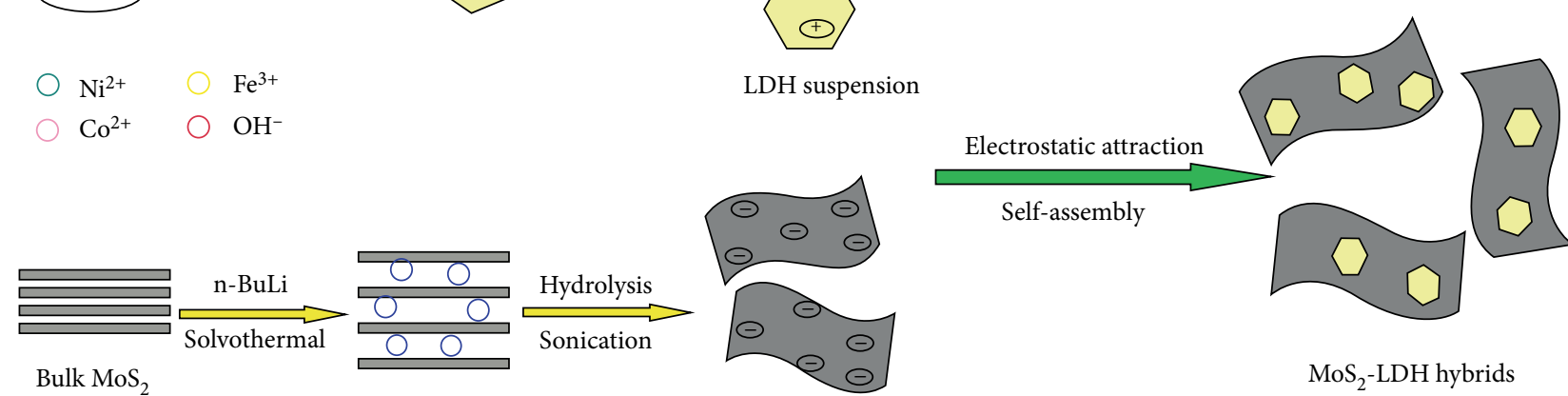

Bulk $\mathrm{MoS}_{2}$

$\bigcirc \mathrm{Li}^{+}$

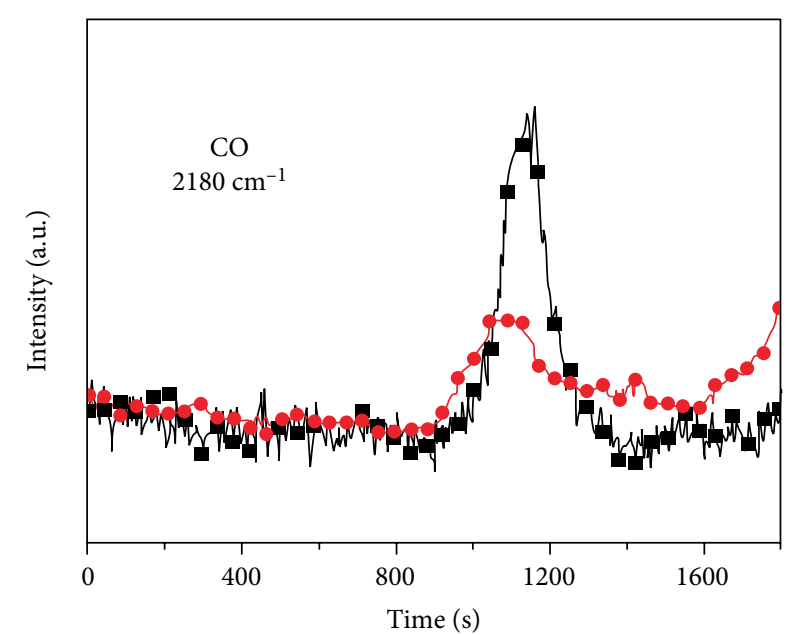

$\rightarrow \mathrm{EP}$

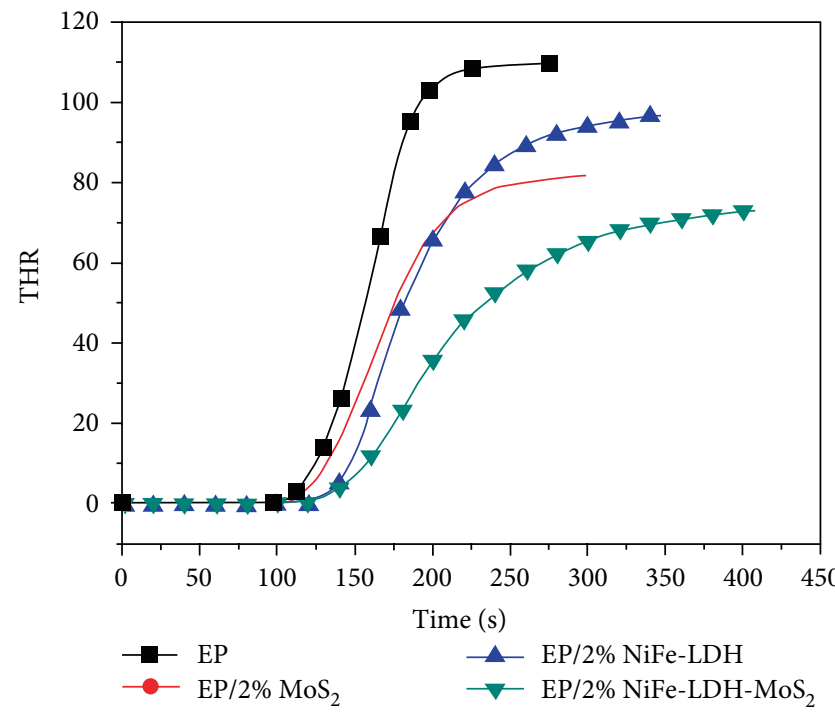

(b)

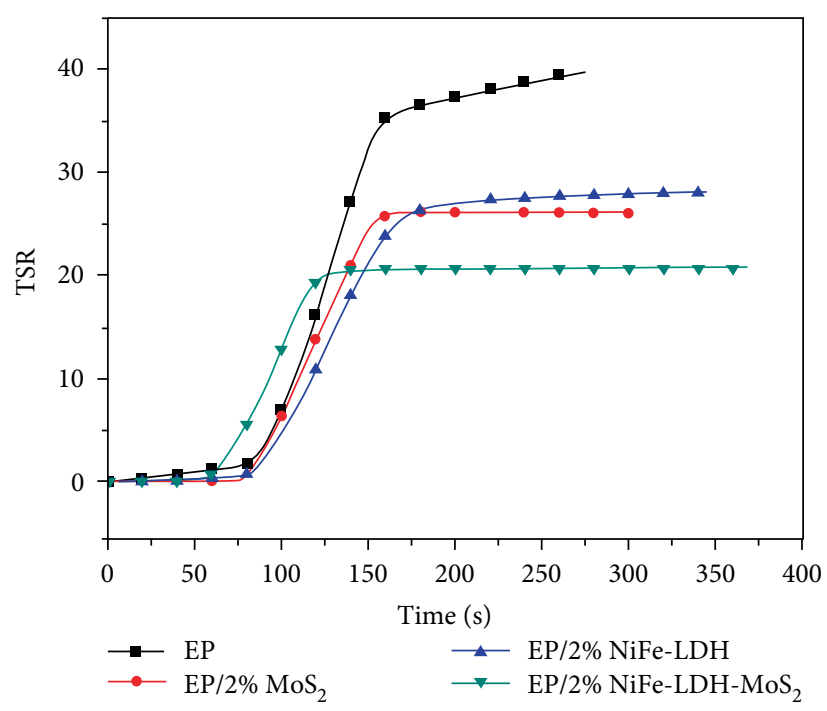

(c)

(a)
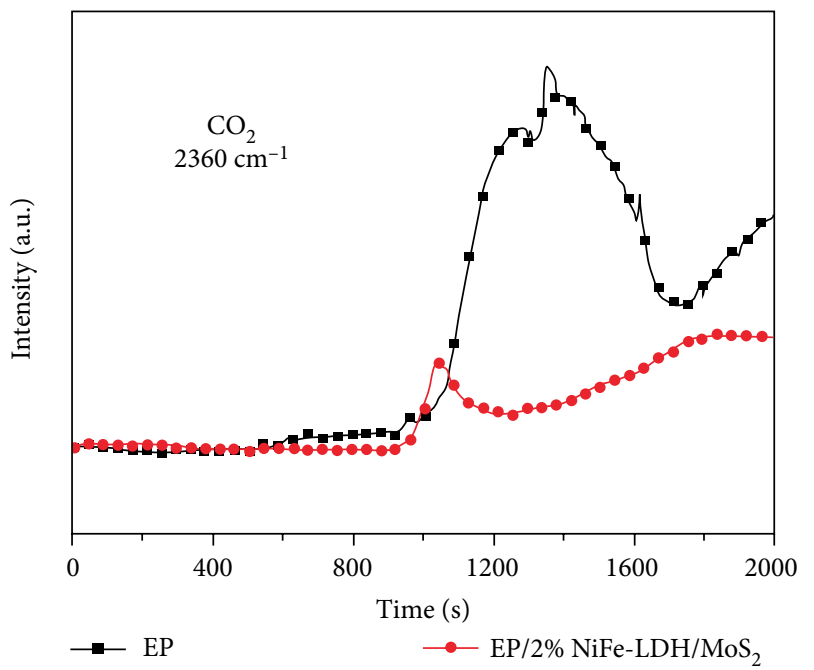

Exfoliated $\mathrm{MoS}_{2}$ nanosheets

a)

$\mathrm{MoS}_{2}$-LDH hybrids 
charred layers in the condensed phase and hinder the diffusion of oxygen and flammable volatile products.

Ren et al. [68] prepared black phosphorene/graphene $(\mathrm{BP} / \mathrm{G})$ composites by high-pressure nano-homogenizer machine (HNHM) and distributed them uniformly in WPU. The addition of graphene could reduce pHRR by $21.2 \%$, and the addition of BP/G could reduce pHRR by $48.18 \%$ when compared with the pristine WPU. This was because the special layered structure of graphene and BP had barrier effects during degradation process, which could prevent materials from oxygen and heat transfer. In addition, BP could form PO• free radicals, diffuse in surrounding gases, and react with $\mathrm{H} \bullet$ or $\mathrm{OH} \bullet$ free radicals produced by polymer under combustion, hence reducing the flame.

\section{Research Progress on Polymer/Two- Dimensional Nanomaterial Flame Retardant Composites}

3.1. Sulfur-Containing Compounds. Various 2D nanosheets, such as molybdenum disulfide $\left(\mathrm{MoS}_{2}\right)$ and tungsten disulfide $\left(\mathrm{WS}_{2}\right)$, have attracted tremendous attention due to the unusual properties associated with their ultrathin nanosheet structures. $\mathrm{MoS}_{2}$ is composed of three stacked atomic layers (S-Mo-S) held together by van der Waals forces [17]. Mechanically exfoliated atomically thin sheets of $\mathrm{WS}_{2}$ have been shown to exhibit high in-plane carrier mobility and electrostatic modulation of conductance similar to $\mathrm{MoS}_{2}$ [69]. These have been extensively studied in the field of polymer flame retardation because of their outstanding mechanical properties, which can be attributed to their small size, typically in the range of 40-180 nm, and their chemical inertness [70].

On the one hand, $\mathrm{MoS}_{2}$ has been used for enhancing the thermal, flame-retardant, and mechanical properties of polymer composites [18-20, 71-83] due to its small size and high thermal stability. For instance, cellulose nanofibers (CNFs) were nano-wrapped with ultrathin $1 \mathrm{~T}$ phase $\mathrm{MoS}_{2}$ nanosheets via chemical crosslinking to produce an aerogel. Thermal and combustion characterization revealed highly desirable properties (thermal conductivity $k=28.09 \mathrm{~mW} \mathrm{~m}^{-1} \mathrm{~K}^{-1}$, insulation $R$ value $=5.2$, limit oxygen index $(\mathrm{LOI})=34.7 \%$, total heat release $=0.4 \mathrm{MJ} \mathrm{m}^{-2}$ ). Considering the inherently low density of this material, there was significant opportunity for its use in a number of insulating applications [72]. Wang et al. reported the synthesis of $\mathrm{MoS}_{2}$ nanosheets via a "thiol-ene" click reaction between defect-rich $\mathrm{MoS}_{2}$ nanosheets with sulfydryl groups and ene-terminated hyperbranched polyphosphate acrylate (HPA), and characterized these nanosheets by FTIR and XPS to confirm their covalent functionalization through C-S bonds. The combustion behavior of unsaturated polyester resin (UPR) composites was also investigated, demonstrating an obvious reduction of $43.2 \%$ and $39.6 \%$ in Peak Heat Release Rate (pHRR) and Total Heat Release (THR), respectively [74]. To solve the problem of homogeneous dispersion of $\mathrm{MoS}_{2}$ nanosheets in a polymer matrix and exact interface control, hierarchical polystyrene@ $\mathrm{MoS}_{2}$ core-shell structures were constructed by combining latex technology and self-assembly of oppositely charged $\mathrm{MoS}_{2}$ nanosheets onto the surface of PS spheres. This method proved to be an efficient and facile approach to fabricate polymer $/ \mathrm{MoS}_{2}$ nanocomposites with good dispersion and improved properties [75].

On the other hand, $\mathrm{MoS}_{2}$ and its derivatives have been used for smoke suppression of various polymers, including polystyrene [17, 84], polyvinyl alcohol [85], epoxy [86-89], polyurethane [90], and polyamide 6 [91]. For example, Zhou et al. [86] reported $\mathrm{LDH} / \mathrm{MoS}_{2}$ hybrids were facilely prepared by self-assembly of exfoliated $\mathrm{MoS}_{2}$ nanosheets and LDH via electrostatic forces. This approach endowed excellent fire resistance to an epoxy matrix, which was reflected by the significantly reduced peak heat release rate, total heat release, and total smoke production (Figure 3). Qiu et al. [88] showed that polyphosphazene nanoparticles (PPN) functionalized with $\mathrm{MoS}_{2}$ nanosheets have been successfully fabricated, followed by high temperature polymerization. The incorporation of $\mathrm{P}$ and $\mathrm{N}$ atoms efficiently reduced the stacking of $\mathrm{MoS}_{2}$ nanolayers and formed a large number of active sites. It was also demonstrated that the introduction of $\mathrm{MoS}_{2} @ \mathrm{PPN}$ nanohybrids significantly improved the flame retardancy of EP. Feng et al. [91] used supramolecular self-assembly to prepare sandwich-like melamine cyanurate/ $\mathrm{MoS}_{2}$ sheets as hybrid flame retardants for PA6. The introduction of $\mathrm{MoS}_{2}$ sheets functioned not only as a template to induce the formation of two-dimensional melamine cyanurate capping layers, but also as a synergist to generate integrated flame-retarding effects in the hybrid sheets, in addition to a high-performance smoke suppressor to reduce the fire hazards of PA6 materials.

$\mathrm{WS}_{2}$ is one of the most commonly used compounds in semiconductor TMS's. In recent years, materials such as $\mathrm{WS}_{2}$ have attracted increased attention in the field of nanocomposite fillers, due to their high thermal and mechanical properties $[69,92]$. Díez-Pascual et al. prepared an inorganic fullerene-like tungsten disulfide (IF-WS ${ }_{2}$ ) lubricant, and then used this to manufacture PPS/IF- $\mathrm{WS}_{2} / \mathrm{CF}$ laminates via melt-blending and hot-press processing. These multiscale laminates exhibited higher ignition points and notably reduced $\mathrm{pHRR}$ compared to PPS/CF alone. The coexistence of micro- and nano-scale fillers resulted in synergistic effects that enhanced the stiffness, strength, thermal conductivity, and flame retardancy of the matrix [70]. Wenelska et al. reported $\mathrm{WS}_{2}$ functionalized with metal oxides (iron oxide and nickel oxide) as a filler for PEs. This showed that composites can provide a certain physical barrier and inhibit the diffusion of heat and gaseous products during combustion [69].

3.2. Phosphorus-Containing Compounds. Phosphorus-containing compounds, including $\alpha$-zirconium phosphate ( $\alpha$-ZrP), black phosphorus (BP), and vanadium dehydrated phosphate $\left(\mathrm{VOPO}_{4}\right)$, may replace halogenated variants that are still widely used in flame retardants. Phosphorous flame retardants can play a role in both the gas phase and condensed phase extinguishing mechanisms during a fire [3]. In the following, different P-containing flame retardants are explored in detail.

3.2.1. $\alpha$-Zirconium Phosphate. $\alpha$ - ZrP is a type of solid acid, which represents a wide range of chemical substances that are able to accept electrons and create coordinate bonds. The 
dehydrogenation of a polymer occurs and these unsaturated sites then lead to crosslinking and ultimately graphitization. Therefore, solid acid-type $\alpha$-ZrP can play an effective role as a crosslinking catalyst through the catalysis of carbonization of the polymer itself during thermal decomposition [93]. However, two main subjects have to be addressed before their further applications as flame retardants: the inherent agglomeration of nano-sized $\alpha$ - ZrP and their incompatibility with polymers [59, 63, 67, 93-114].

Planar-like $\alpha$-ZrP particles have been modified with a kind of cyclophosphazene derivative (named HAC) by a three-step hybridization method [113]. The combination of (intumescent flame retardant) IFR and HAC can significantly improve the yield and graphitization of these residues, make them more stable, compact, and continuous, and allowing the inhibition of the thermo-oxygen contact of the underlying poly (vinyl alcohol) (PVA). In addition, the mechanical properties of such composites could be enhanced and toughened by specific HAC content.

Xie et al. [63] reported a macromolecular charring agent (MCA) decorated with zirconium phosphate nanosheets. This was then combined with ammonium polyphosphate (APP) to reduce the flammability of polypropylene. The limiting oxygen index (LOI) of PP/ZrP-d-MCA/APP reached $32.5 \%$ and a UL-94-V0 rating when the content of ZrP-d-MCA and APP was $5 \% \mathrm{wt}$ and $15 \% \mathrm{wt}$, respectively. The flame-retardant mechanism of ZrP-d-MCA/APP was further studied. It was shown that a $\mathrm{ZrP}$ nanosheet could effectively catalyze the carbonization reaction of MCA to form a closed micro-nano carbon cage during the combustion process.

$\mathrm{Fu}$ et al. [114] reported the synthesis of a hybrid cardanol-derived zirconium phosphate ( $\mathrm{CZrP})$ from the renewable resource cardanol. Their results showed that the enlarged interlayer spacing of CZrP facilitated the homogeneous dispersion of the nano-additive in an epoxy resin. The suppressed fire hazards of EP were attributed to the physical barrier effect induced by the 2D-CZrP. In addition, the tensile strength and the elongation at break were enhanced simultaneously due to the reinforcing effect of the inorganic platelet and the plasticizing effect of the long alkyl chains in this unique hybrid.

\subsubsection{Black Phosphorus and Dehydrated Vanadyl}

Phosphate. Mono or multi-layer BP is a two-dimensional nanomaterial with distinct physical/chemical properties due to dimensionality effects $[21,68]$. BP can catalyze the formation of char and capture free radicals, and its unique layered structure can also serve as a physical barrier for insulation from heat and oxygen during the combustion process [115]. For example, Qiu et al. [115] reported a stable cross-linked polyphosphazene-functionalized BP (BP-PZN) synthesized in the presence of air. The BP-PZN was developed with abundant $-\mathrm{NH}_{2}$ groups via a one-pot polycondensation of 4,4' diaminodiphenyl ether and hexachlorocyclotriphosphazene on the surface of BP nanosheets. Results demonstrated that the introduction of $2 \mathrm{wt} \%$ BP-PZN distinctly improved the flame-retardant properties of EP. For instance, there was a $59.4 \%$ decrease in pHRR and a $63.6 \%$ reduction in THR. The diffusion of pyrolysis products from an EP during combustion was obviously suppressed after incorporating BP-PZN nanosheets. Digital photos, SEM, and Raman spectra of char residue from such an EP are shown in Figure 4.

$\mathrm{VOPO}_{4}$ is a new two-dimensional graphene material with a typical layered structure where $\mathrm{VOPO}_{4}$ has been formed by connecting $\mathrm{VO}_{6}$ octahedra with vertex-sharing with phosphate $\mathrm{PO}_{4}$ tetrahedra. An ultrathin $\mathrm{VOPO}_{4}$ nanosheet is expected to improve the thermal stability, flame retardancy, and mechanical properties of a polymer. In addition, $\mathrm{VOPO}_{4}$ nanosheets can also catalyze the dehydrogenation of a polymer and promote the carbonization of a polymer [116]. For example, a $\mathrm{VOPO}_{4}$ ultrathin nanosheet was synthesized by a simple refluxing method and then modified with typical organic surfactants (VOP) [117]. Afterwards, this nanosheet was incorporated into PS for reducing fire hazards. With a loading of 1 wt $\%$ of modified VOP, $T_{5 \%}, T_{10 \%}, T_{50 \%}$, and $T_{\max }$ values increased $15,22,29$, and $33^{\circ} \mathrm{C}$, respectively. Furthermore, the presence of VOP nano-sheet reduced the decomposition rate of PS and increased the char residue.

3.3. Nitrogen-Containing Compounds. As a structural analogue of graphene, monolayer 2D hexagonal boron nitride (h-BN), with the alternate use of boron and nitrogen atoms instead of carbon atoms in the 2D conjugate layers, has attracted increased attention due to its high-temperature stability, excellent thermal conductivity, superior chemical inertness, and low friction coefficients $[16,118]$. Considering the ionic properties of the $\mathrm{B}-\mathrm{N}$ bond in the boron nitride layer, which is different from the covalent $\mathrm{C}-\mathrm{C}$ bond of graphene, boron nitride nanosheets have outstanding resistance to oxidation (the degradation temperature in air is $840^{\circ} \mathrm{C}$ ) and corrosion [119]. Most notably, boron nitride with a $2 \mathrm{D}$ morphology and high thermal resistance can be used as an effective nano flame retardant to improve the thermal stability, thermal conductivity, and flame retardancy of a polymer.

It is believed that $\mathrm{H}-\mathrm{BN}$ can be used as a rigid barrier for the transfer of decomposed fragments due to its highly thermal stability via its layered structure, thus improving the fire safety of polymers [11-16, 42, 51, 118-133]. Zhang et al. [16] reported a multifunctional CPBN that was successfully prepared via the wrapping of a phytic acid doped polypyrrole shell, followed by the adsorption of copper ions. The significant suppression of $\mathrm{CO}$ and $\mathrm{HCN}$ release could be observed from a TG-IR test. Tensile tests showed that the addition of CPBN was beneficial to the mechanical properties of TPU.

Additionally, super paramagnetic zinc ferrite (ZF) has been used to modify the surface of boron nitride nanosheets (BNN) via a typical solvothermal method [133]. The prepared ZF-BNNS nanofiller was then loaded in an EP and placed in a weak magnetic field $(0.05 \mathrm{~T})$ to achieve an orderly orientation of the EP matrix. Results showed that this weak magnetic field could adjust the orderly arrangement of ZF-BNNS nanofillers in an EP matrix, and well-ordered ZF-BNNS nanofillers were superior to randomly distributed ZF-BNNS nano-fillers in enhancing EP fire resistance.

With the rapid development of electronic devices, there is an increasing demand for high heat-dissipation polymers [13, $118,126,129]$. We found that a high thermal conductivity (TC) is also an important factor for the high flame retardancy 


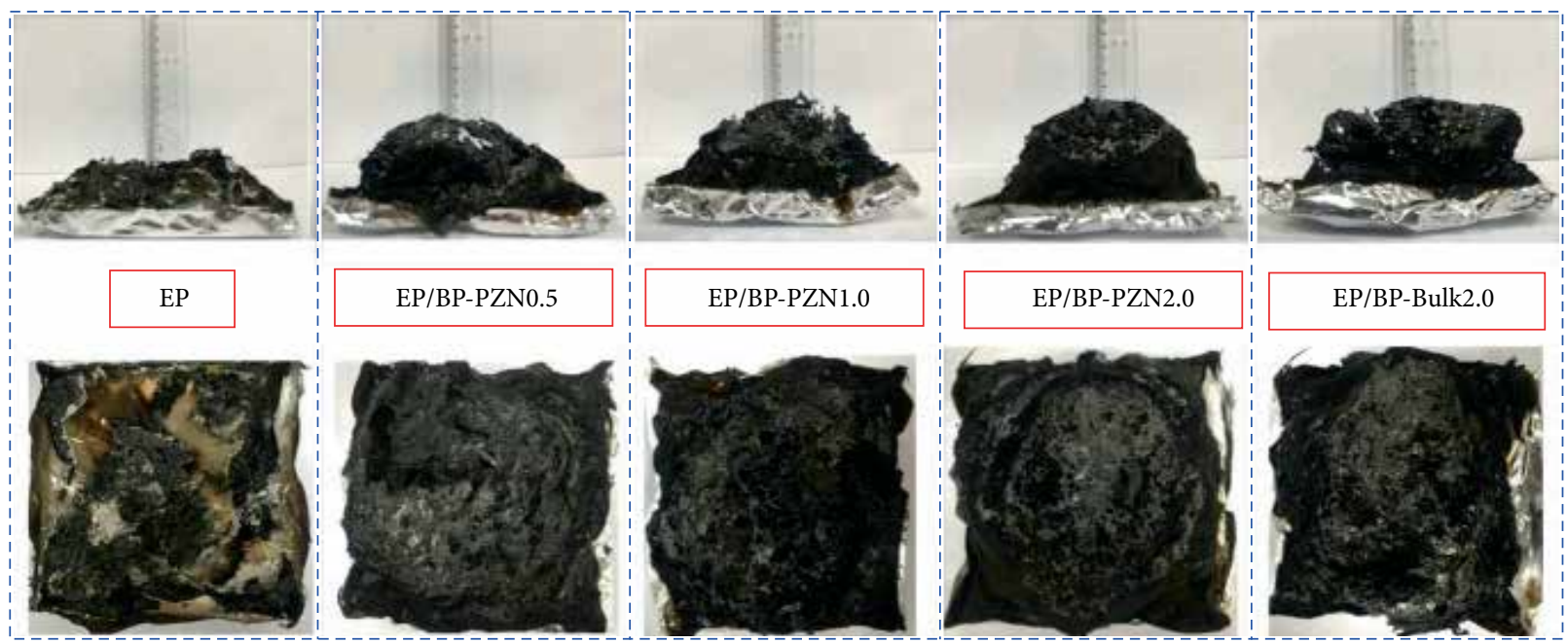

(a)
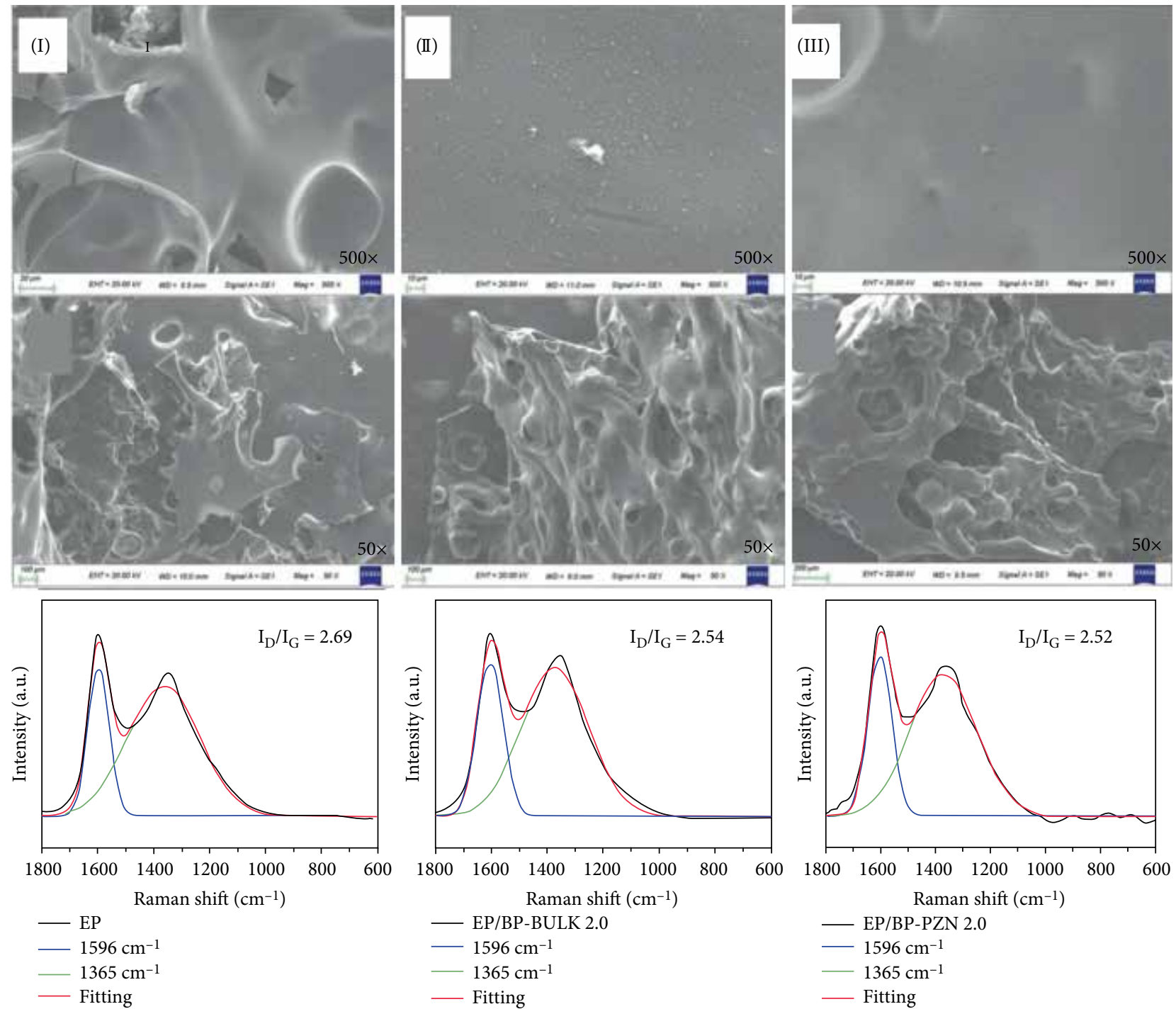

- EP/BP-PZN 2.0

$-1596 \mathrm{~cm}^{-1}$

$-1365 \mathrm{~cm}^{-1}$

— Fitting

(b)

FIGURE 4: (a) Micrographs of external residues from a top and side view for EP and its nanocomposites. (b) SEM images and Raman spectra of external and interior char residues for (I) EP, (II) EP/BP-Bulk2.0, and (III) EP/BP-PZN2.0 nanocomposites. Adapted from [115]. 


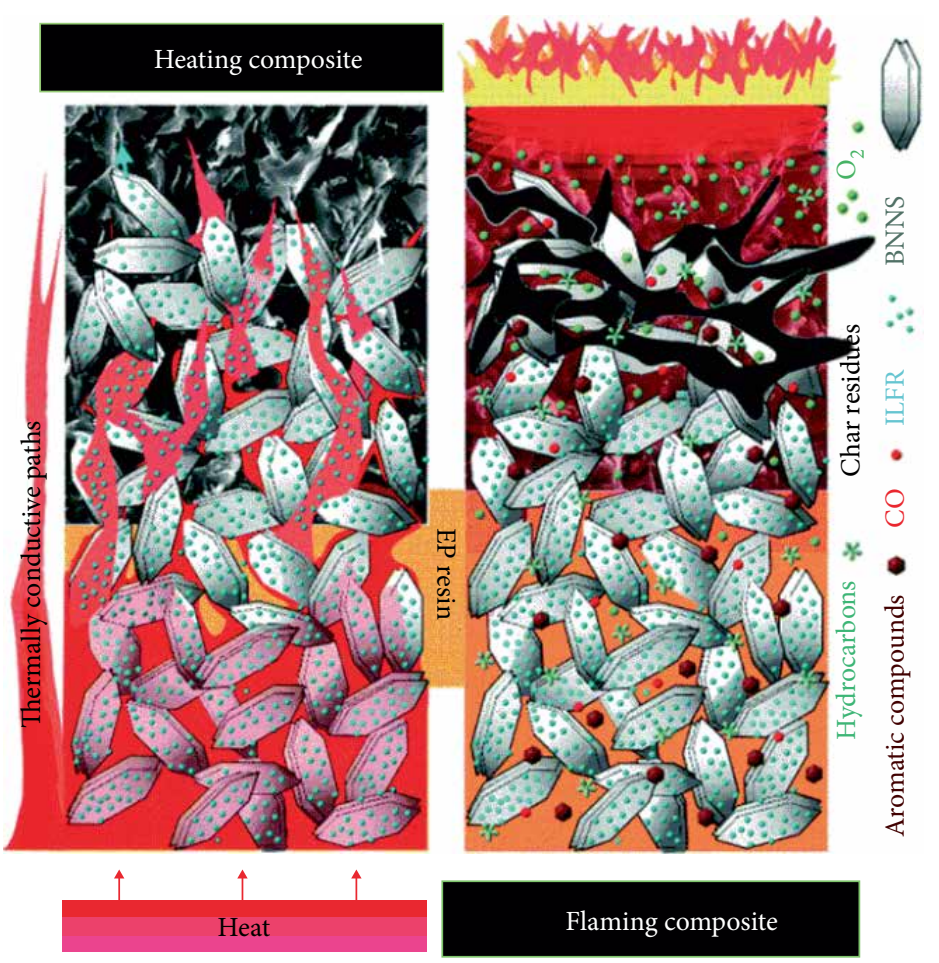

(a)

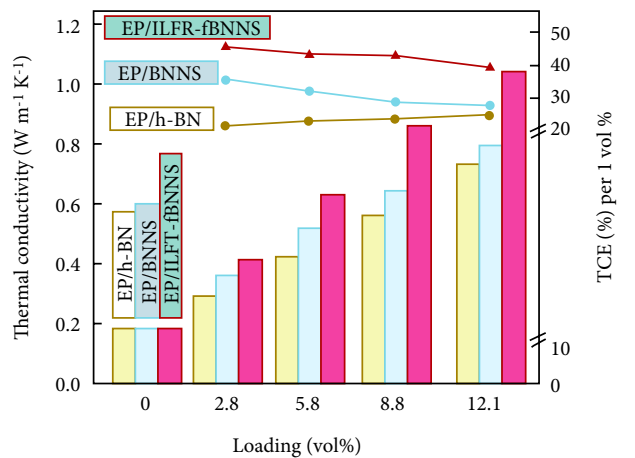

(b)
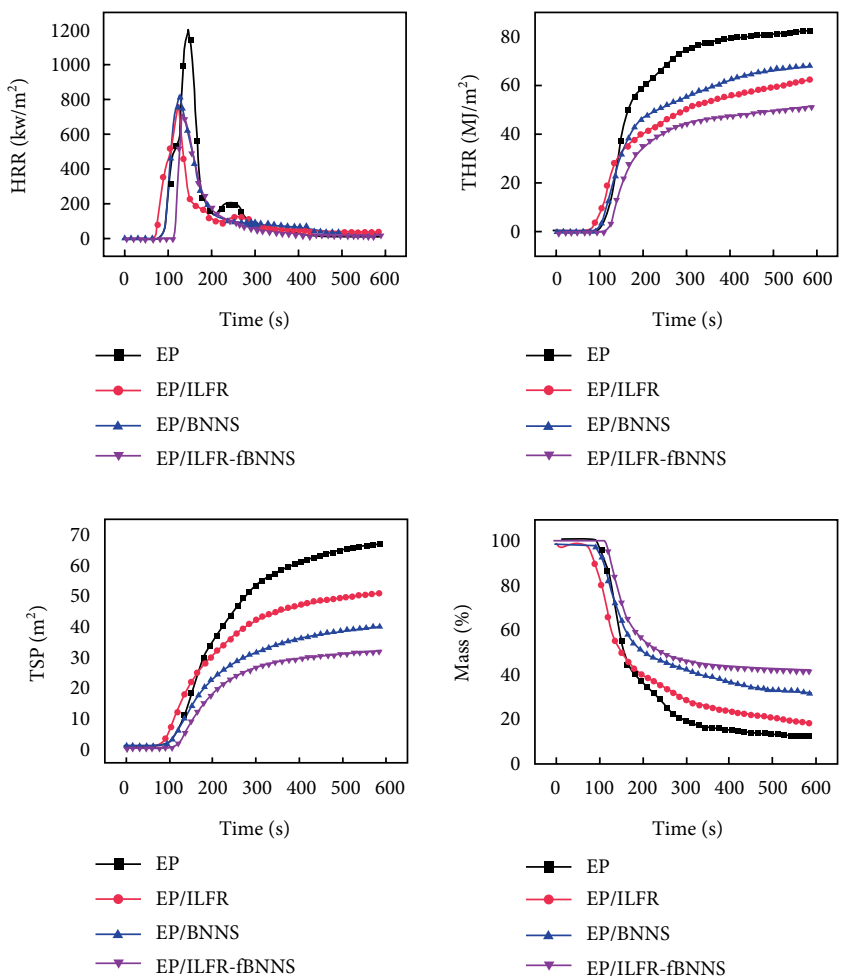

(c)

FIgURE 5: (a) Schematic illustration of thermal conduction and flame retardation mechanisms of EP/ILFR-fBNNS nanocomposites. (b) Thermal conductivity of EP/h-BN, EP/BNNS, and EP/ILFR-fBNNS composites. (c) The HRR, THR, TSP, and mass loss versus time curves of neat EP, EP/ILFR, EP/BNNS 12.1\% vol and EP/ILFR-fBNNS 12.1\% vol samples obtained from cone calorimeter tests. Adapted from [118].

of boron nitride nanosheets. Non covalent ionic liquid flame retardant-functionalized boron nitride nanosheets (ILFRfBNNSs) were used as a multifunctional nano-additive for fabricating EP-based nanocomposites with both superior TC and flame retardancy [118]. These ILFR-fBNNS trigger resin crosslinking at a given temperature, while conferring 
TABLE 1: Formulations and flammability test results of TPU composites [45].

\begin{tabular}{|c|c|c|c|c|c|c|c|}
\hline Sample & TPU [g] & APP [g] & $\mathrm{CS}[\mathrm{g}]$ & ACS [g] & OMMT $[\mathrm{g}]$ & LOI [\%] & UL-94 rating \\
\hline TPU & 100 & 0 & 0 & 0 & 0 & $20.8 \pm 0.3$ & None \\
\hline TPU/APP/CS & 90 & 5 & 5 & 0 & 0 & $26.6 \pm 0.2$ & None \\
\hline TPU/APP/ACS & 90 & 5 & 0 & 5 & 0 & $28.6 \pm 0.1$ & $\mathrm{~V}-2$ \\
\hline $\begin{array}{l}\text { TPU/APP/ACS/ } \\
\text { OMMT }\end{array}$ & 90 & 4.5 & 0 & 4.5 & 1 & $29.0 \pm 0.1$ & $\mathrm{~V}-0$ \\
\hline
\end{tabular}

TABLE 2: Burning parameters of two-dimensional nanomaterials/polymer composites.

\begin{tabular}{lccccc}
\hline Polymer matrix & Recipes & pHRR & THR & TSR & Year and reference \\
EP & $2 \mathrm{wt} \% \mathrm{MoS}_{2} @ \mathrm{PPN}$ & $-30.7 \%$ & $-23.6 \%$ & $-43.0 \%$ & $2018[88]$ \\
PE & $2 \mathrm{wt} \% \mathrm{WS}_{2} / \mathrm{Ni}_{2} \mathrm{O}_{3}$ & $-34.9 \%$ & $-17.0 \%$ & $/$ & $2018[69]$ \\
EP & $6 \mathrm{wt} \% \mathrm{MCPA}^{-Z \mathrm{P}}$ & $-42.2 \%$ & $-21.4 \%$ & $/$ & $2018[114]$ \\
EP & $2 \mathrm{wt} \% \mathrm{BP}-\mathrm{PZN}$ & $-59.4 \%$ & $-63.6 \%$ & $-32.0 \%$ & $2019[115]$ \\
PS & $3 \mathrm{wt} \% \mathrm{C}-\mathrm{VOP}$ & $-48.3 \%$ & $-43.6 \%$ & $/$ & $2017[117]$ \\
EP & $3 \mathrm{wt} \% \mathrm{ZF}-\mathrm{BNNS}$ & $-48.5 \%$ & $/$ & $-6.5 \%$ & $2019[133]$ \\
PP & $4 \mathrm{wt} \% \mathrm{Co}-\mathrm{OMt} / 19 \mathrm{wt} \% \mathrm{IFR}$ & $-63.8 \%$ & $-17.6 \%$ & $/$ & $2017[143]$ \\
EP & $7 \mathrm{wt} \% \mathrm{fCD}-\mathrm{DBS}-\mathrm{Ph}-\mathrm{LDH}$ & $-72.3 \%$ & $/$ & $-63.7 \%$ & $2016[180]$ \\
EP & $2 \mathrm{wt} \% \mathrm{RGO}-\mathrm{LDH} / \mathrm{CuMoO} 4$ & $-47.6 \%$ & $-28.5 \%$ & $-38.0 \%$ & $2018[191]$ \\
PS & $4 \mathrm{wt} \% \mathrm{~g}-\mathrm{C}_{3} \mathrm{~N}_{4} / \mathrm{DAHPi}$ & $-42.8 \%$ & $-20.8 \%$ & $/$ & $2017[233]$ \\
EP & $2 \mathrm{wt} \% \mathrm{ZIF}-67 / \mathrm{RGO}-\mathrm{B}$ & $-65.1 \%$ & $-41.4 \%$ & $-37.6 \%$ & $2019[223]$ \\
EP & $2 \mathrm{wt} \% \mathrm{MoS}_{2}-\mathrm{CNTs}$ & $-26.4 \%$ & $-31.3 \%$ & $/$ & $2015[19]$ \\
\hline
\end{tabular}

improvements in the dispersion and interfacial adhesion, thereby forming a thermally conductive network with reduced interfacial phonon scattering and a high-efficiency nano-barrier network acting synergistically with ILFR-induced char residues during thermal degradation. Figure 5 shows the relationship between thermal conductivity and flame retardancy.

Liu et al. [13] demonstrated the use of exfoliated h-BN nanosheets as a high-performance, binder-free fire-resistant coating for wood. The surface of a wood substrate remained intact after exposure to fire. The anisotropic thermal conductivity and low thermal diffusivity and effusivity of $\mathrm{h}-\mathrm{BN}$ make it an excellent wood protection coating.

3.4. Silicon-Containing Compounds. Among nanofillers, layered silicates are the most widely used for preparing polymer nanocomposites because they are readily available and well characterized. Montmorillonite (MMT) is a crystalline 2:1 layered clay mineral where a central alumina octahedral sheet is sandwiched between two silica tetrahedral sheets, and it has been shown to be safe in animals or humans [134, 135].

There are various methods that have been used to realize flame-retardant polymer/montmorillonite nanocomposites, including intercalation, synergy, organic modification, hybridization, layer-by-layer assembly, and self-assembly [134-152]. Inspired by nacre, Xie et al. [151] developed a super-efficient fire-safe nanocoating based on carboxymethyl chitosan and modified MMT via one-step self-assembly. The nanocoating possessed a well-arranged nacre-like hierarchical microstructure, exhibiting high transparency and specific nacre-like iridescence. Most importantly, the peak heat release rate, total heat release, peak smoke production rate, and total smoke production of polyurethane foam were decreased by $84.1 \%$, $89.4 \%, 84.4 \%$, and $95.2 \%$, respectively. A polyimide (PI) composite aerogel was also prepared by freeze-drying with graphene and MMT as additives [141]. Through the strong interaction between the two components, GO/MMT complexes could be synergistically dispersed in water and have good dispersion in a PI matrix, thus endowing the composite aerogel with enhanced mechanical, thermal, and flame-retardant properties. In order to improve the flame retardant performance of IFR/PP composites, OMMT intercalation cobalt compounds (Co-OMt) have been prepared and modified using acidified chitosan to further expand the interlayer spacing of MMT [143]. CO-OMT/IFR/PP nanocomposites have been prepared by a melt blending method. With addition of $4 \%$ mass Co-OMt, 4\% mass Co-OMt/IFR/PP nanocomposites have surpassed a UL-94 V-0 rating, with an LOI value as high as $32.1 \%$.

The use of MMT as a synergic additive to flame retardants for designing polymers with better flame-retardant properties has already been extensively studied $[45,153-166]$. The effect of $\mathrm{APP} /$ zinc borate (ZB) for making highly efficient flame retardants and ceramics of ethylene-vinyl acetate/mica powder/organic modified montmorillonite (EVA/MP/OMMT) composites has been shown [166]. In a fire test, the EVA/MP/ OMMT/APP/ZB system displayed obvious flame-retardant features, showing a much lower THR and TSR than pure EVA. Zhang et al., [45] reported a flame retardant (ACS) prepared by crosslinking chitosan with bis-(4-formylphenyl)-phenyl-phosphonate. Flame-retardant TPU composites were then prepared by melt blending of ACS, APP, and OMMT. For TPU 


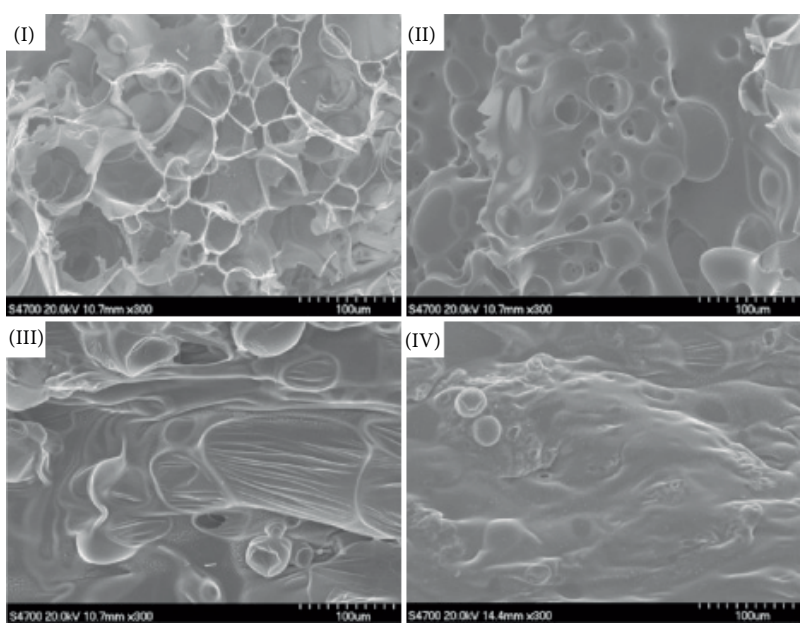

(a)

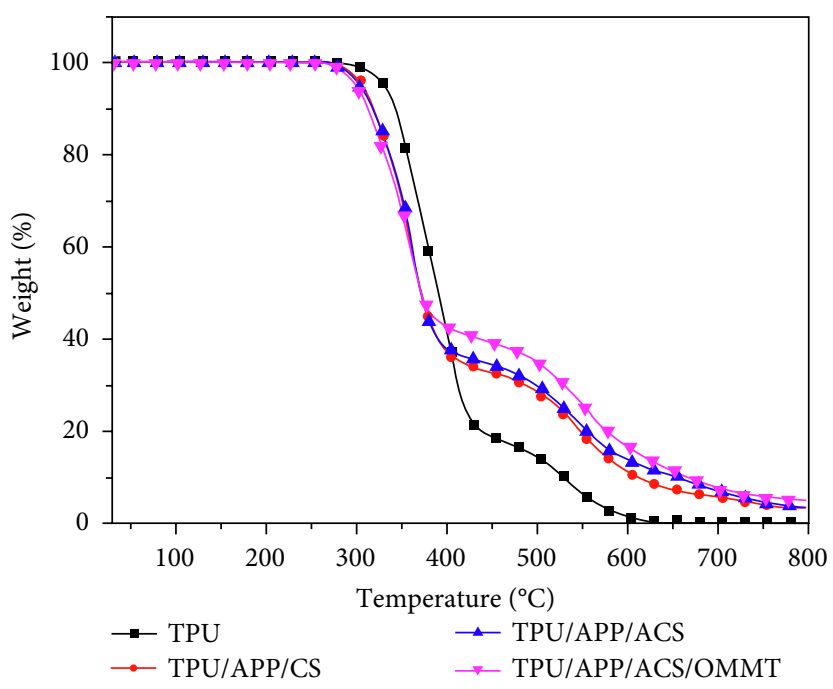

(b)

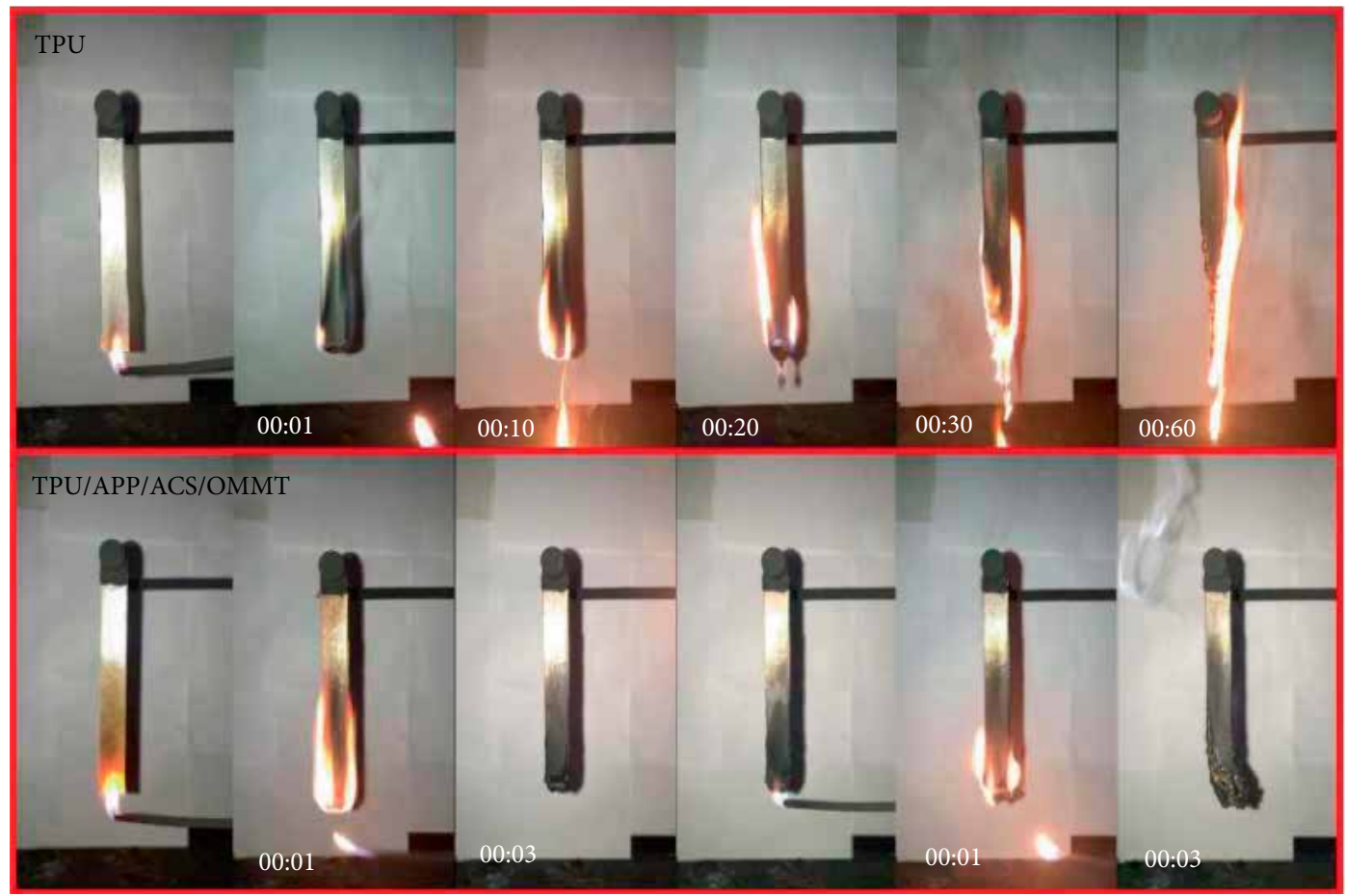

(c)

Figure 6: (a) SEM images of the surfaces residues of (I) neat TPU, (II) TPU/APP/CS, (III) TPU/APP/ACS, and (IV) TPU/APP/ACS/OMMT. (b) TGA curves of TPU composites in air. (c) Screenshots from UL-94 test videos of TPU and TPU/APP/ACS/OMMT samples. Adapted from [45].

samples containing $10 \%$ flame retardant, the LOI increased from 20.8 to 29.0 , the UL-94 rating increased from no to $\mathrm{V}-0$, and the pHRR decreased from 1090 to $284 \mathrm{~kW} / \mathrm{m}^{2}$, respectively. The test results for added OMMT and non-added samples are shown in Figure 6 and Table 1.

3.5. Layered Double Hydroxides. Layered double hydroxides (LDH) are a kind of synthetic anionic clay with host and guest nano-layered materials, which contain positively charged metal hydroxide nanosheets, intercalated anions, and water molecules [167]. LDHs can be represented by the chemical formula $\left[\mathrm{M}_{1-x}{ }^{2+} \mathrm{M}_{x}^{3+}(\mathrm{OH})_{2}\right]^{x+} \cdot\left[\mathrm{A}_{x / n}{ }^{n-} \cdot \mathrm{yH}_{2} \mathrm{O}\right]^{\mathrm{x}-}$, where $\mathrm{M}^{2+}$, $\mathrm{M}^{3+}$, and $\mathrm{A}^{\mathrm{n}-}$ represent divalent metal cations, trivalent metal cations, and an inorganic or organic anion with negative charge $n$, respectively [168]. When used as flame retardant for polymer materials, it has been shown that the flame-retardant mechanism of LDHs are via the "barrier effect" of nano-layers, inert gas dilution of oxygen and the formation of ceramic-like materials [169].

LDHs can be directly used as flame retardant additives because of their unique chemical properties and layered structures [170-177]. For example, flexible polyurethane foam with 


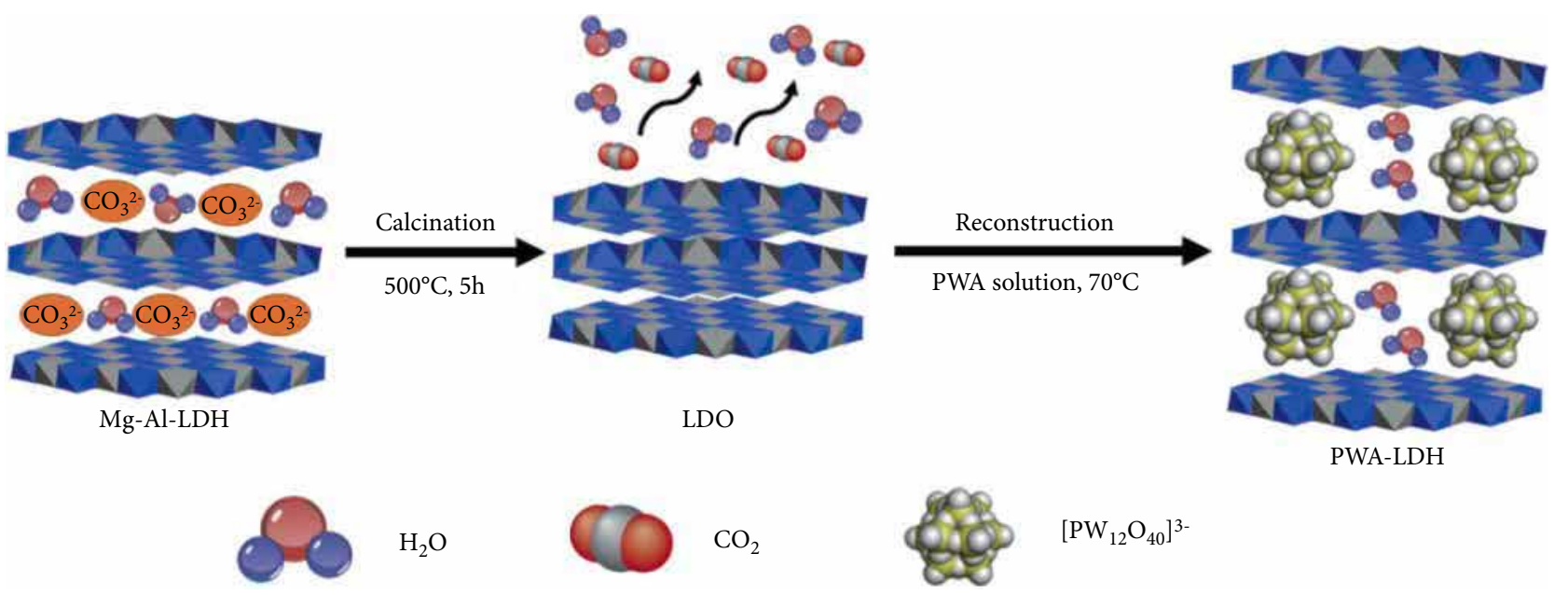

(a)
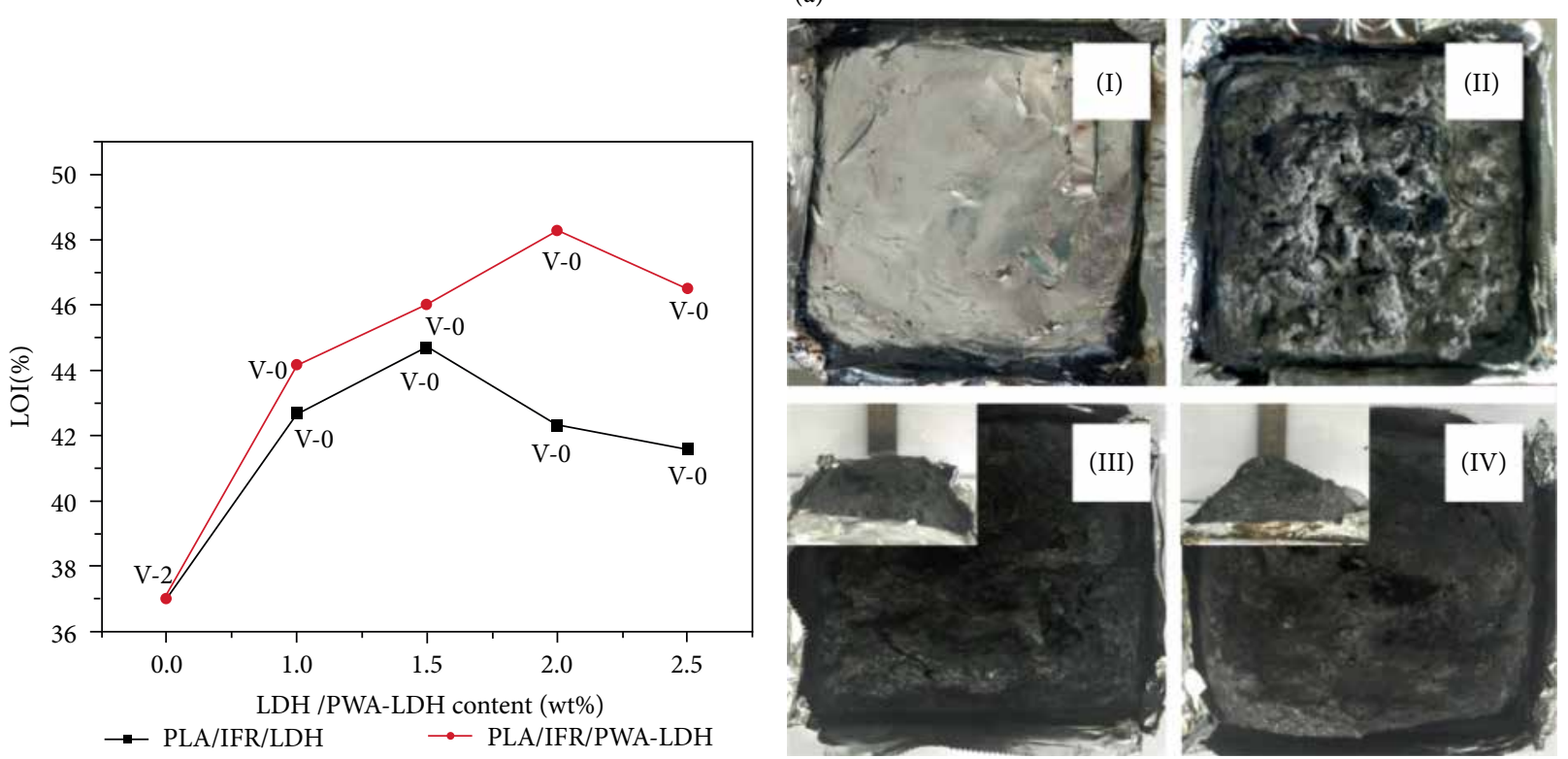

(b)

(c)

Figure 7: (a) The preparation process of PWA-LDH. (b) The LOI and UL-94 results of PLA composites. (c) Digital photos of (I) PLA, (II) PLA/IFR, (III) PLA/IFR/2.0LDH, and (IV) PLA/IFR/2.0PWA-LDH samples after cone calorimeter tests. Adapted from [167].

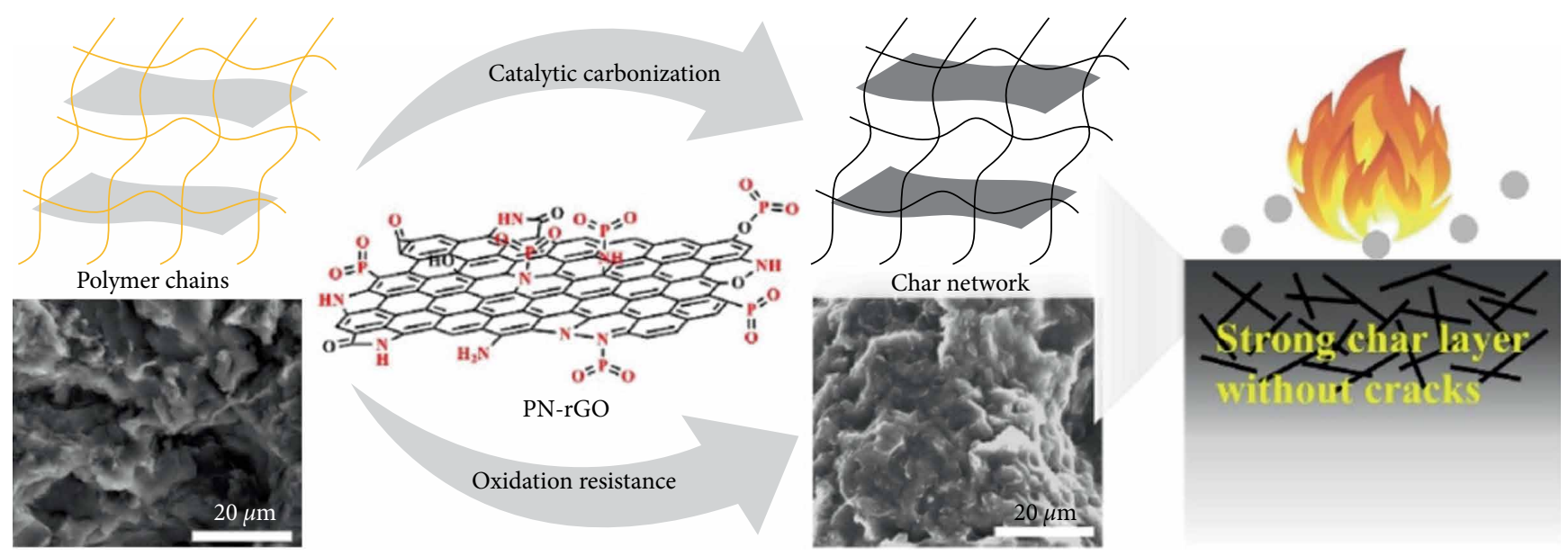

FIGURE 8: Schematic illustration of PN-rGO improving oxidation resistance of the char layer and catalytic carbonization capacity for EP chains. Adapted from [214]. 


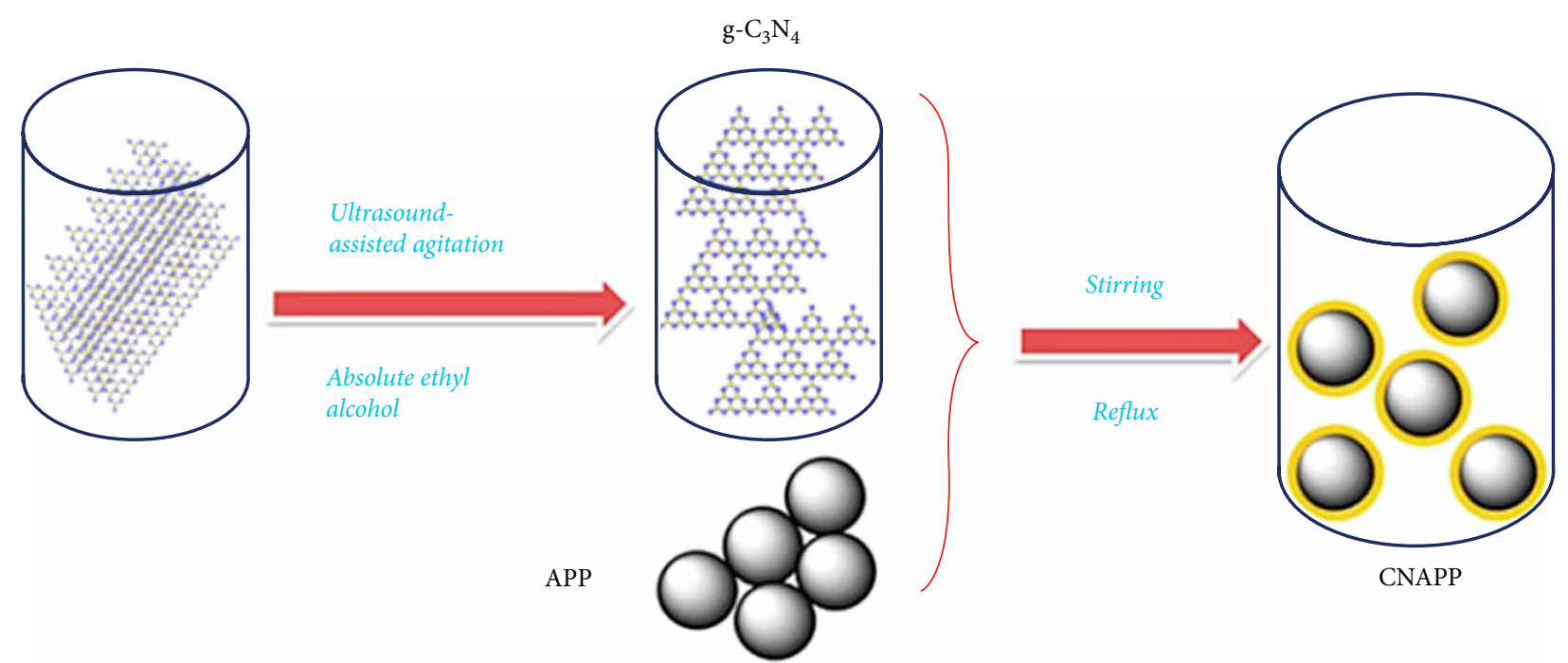

(a)
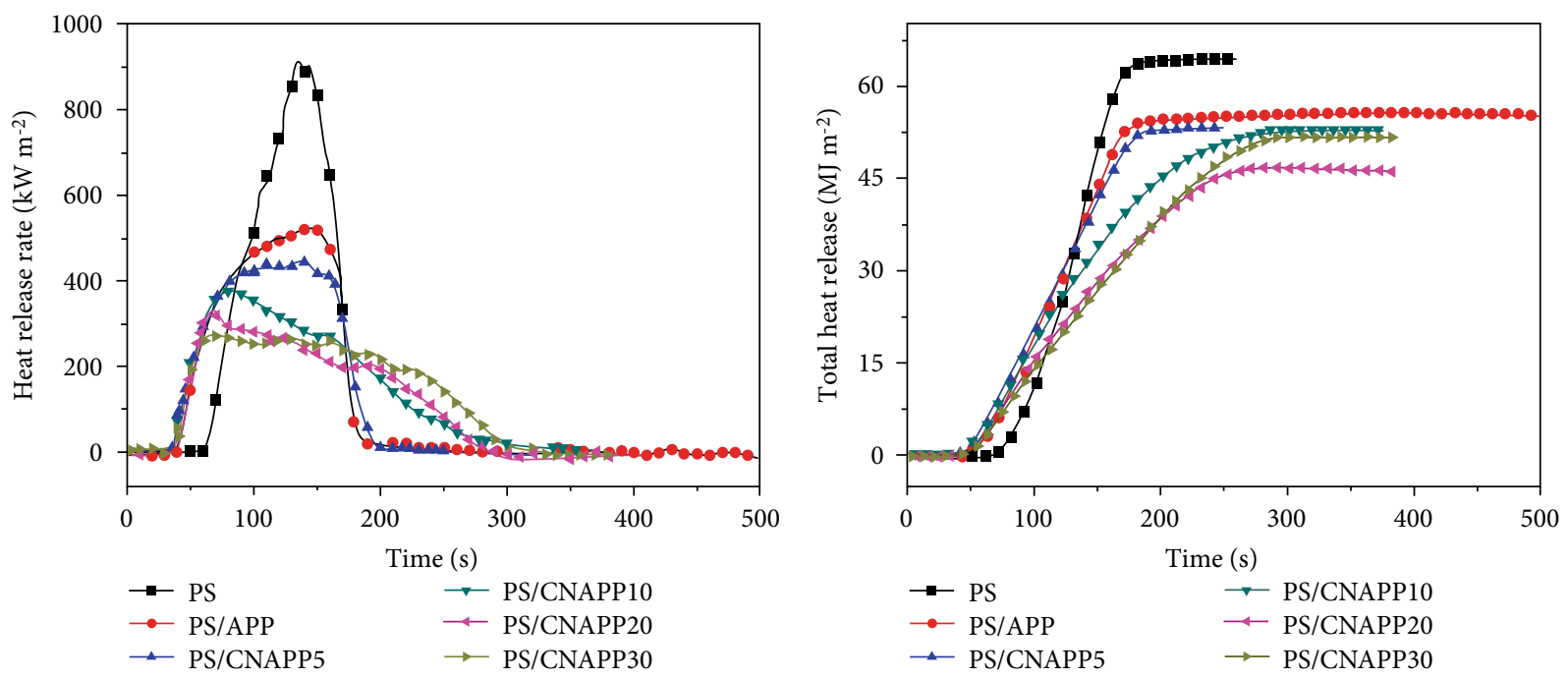

(b)
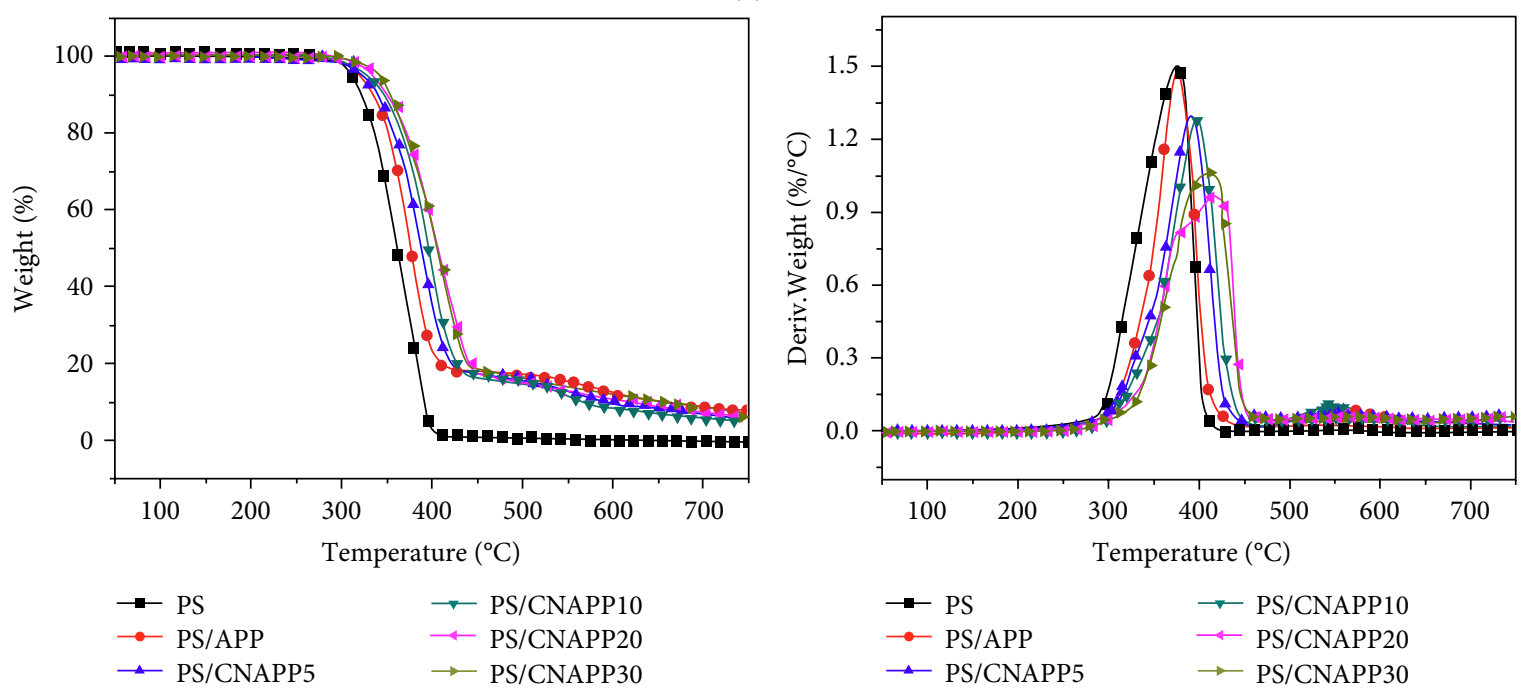

(c)

FigURE 9: (a) The preparation process of CNAPP. (b) The HRR and THR curves of PS and its composites. (c) TG and DTG curves of PS and its composites. Adapted from [232]. 


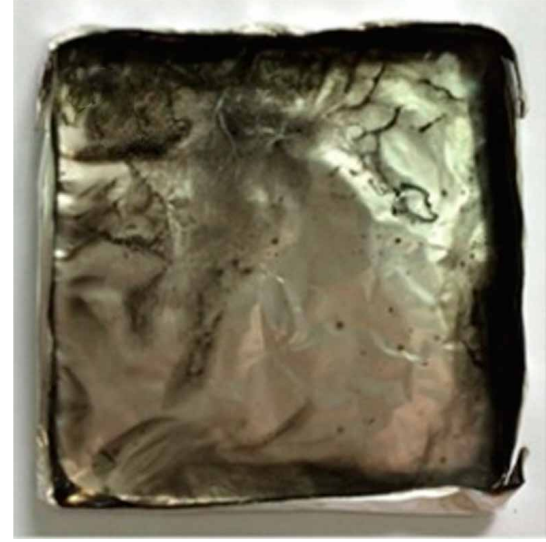

(a)

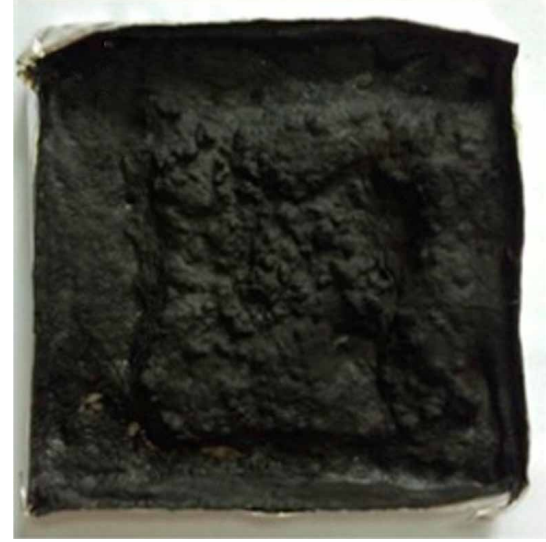

(d)

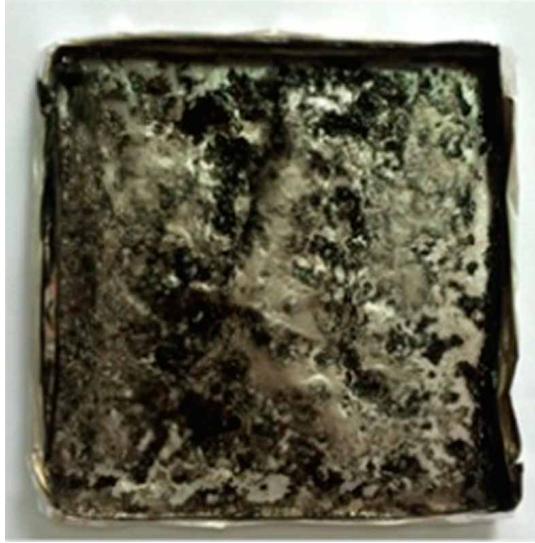

(b)

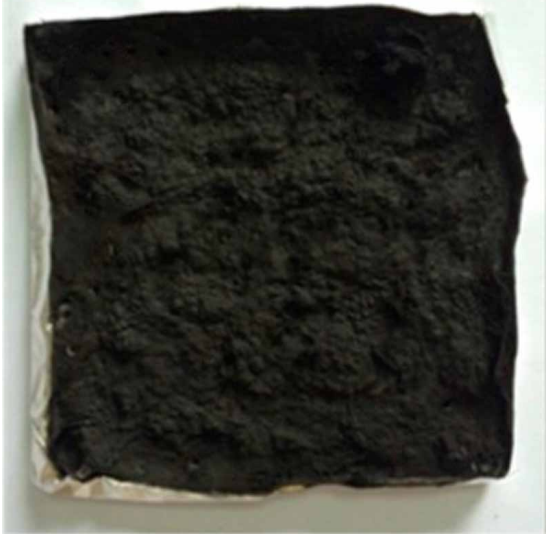

(e)

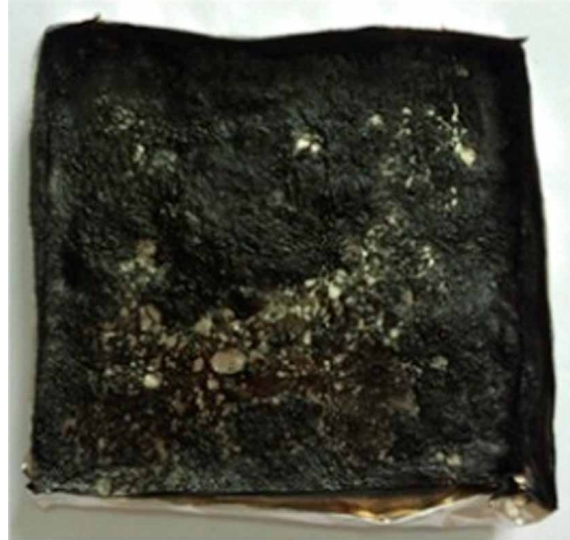

(c)

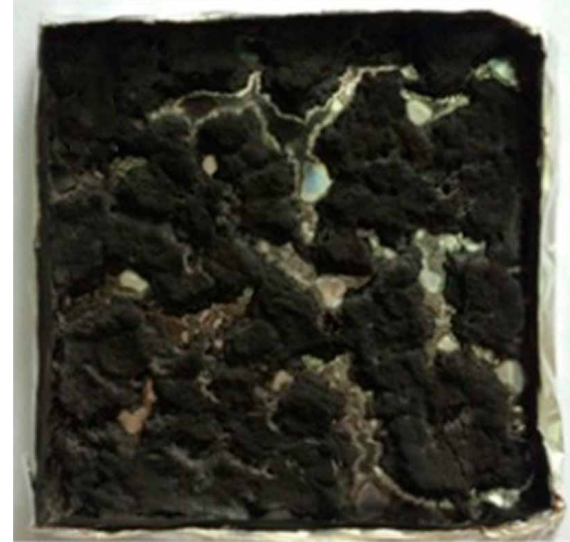

(f)

Figure 10: Digital photos of char residues of (a) PS, (b) PS/APP, (c) PS/CNAPP5, (d) PS/CNAPP10, (e) PS/CNAPP20, and (f) PS/CNAPP30 after the cone calorimetry measurement. Adapted from [232].

a density of $40 \pm 2 \mathrm{~kg} \mathrm{~m}^{-3}$ was prepared by combining LDH and kraft lignin (a byproduct of the pulp and paper industry) with phosphorous polyol (E560) [175]. The effects of fillers on the mechanical properties and combustion properties of fibers were then studied. The presence of such low amounts of lignin by itself did not increase the flame retardancy of FPF, but the addition of E560 increased the charring efficiency, while the addition of $\mathrm{LDH}$ contributed to reinforcing the char layer, yielding a more cohesive protective layer that decreased the pHRR to $47 \%$ as compared with an unfilled foam $0 \mathrm{E}$. Wang et al. [176] investigated the synergistic effects of trace amounts of chloride on char formation and flame retardancy of linear low density polyethylene (LLDPE) filled with NiAl-LDHs. Their results showed that the char yield of $20 \% \mathrm{LDH} / \mathrm{LLDPE}$ (20 wt $\%$ NiAl-LDH) increased from $10.4 \%$ to $49.6 \%$ with the addition of $0.5 \mathrm{wt} \% \mathrm{NH}_{4} \mathrm{Cl}$.

Moreover, the modification of LDHs via the intercalation of some flame-retardant molecules has been shown to be very effective in improving their compatibility with polymer matrices and flame retardants[44, 60, 65, 66, 167, 168, 178-185]. Zhang et al., prepared MgAl-LDH intercalated with phosphotungstic acid (PWA-LDH) by a reconstruction method and melted it with IFR and poly (lactic acid) (PLA) to prepare a flame-retardant biodegradable resin. Their studies showed that the maximum LOI value of composite materials containing $18.0 \mathrm{wt} \%$ IFR and $2.0 \mathrm{wt} \%$ PWA-LDH was $48.3 \%$, passed the UL-94 V-0 rating, and the $\mathrm{pHRR}$ of pure PLA was significantly reduced from $306.3 \mathrm{kw} / \mathrm{m}^{2}$ to $40.1 \mathrm{kw} / \mathrm{m}^{2}$ [167]. As shown in Figure 7, the introduction of LDH into PLA/IFR composites significantly improved the flame retardancy of the condensed phase. By designing composite multi-modifiers with varied functions, multifunctional intercalation of LDHs has been developed, including functionalized hydroxypropyl-sulfobutyl-beta-cyclodextrin (sCD), phytic acid ( $\mathrm{Ph}$ ), sodium dodecylbenzenesulfonate (SDBS), and chalcone, and these functions have been transferred to epoxy materials using nanocarriers [180]. Studies have shown that at only $7 \mathrm{wt} \%$ fCD-DBS-Ph-LDH, the resultant EP nanocomposites passed the UL-94 V-0 rating. Compared with a pure epoxy resin, the pHRR $(-72 \%)$ in a cone calorimeter test decreased significantly.

Lastly, the modification of LDHs via the covering surfaces with hydrophobic flame-retardant molecules is also generally believed to be very effective in improving their compatibility with other polymer matrices for flame retardation $[40,44,66$, 179, 186-194]. DBS intercalated LDH (LDH-DBS) nanosheets have been surface-assembled by an ultrafine $\mathrm{Ni}(\mathrm{OH})_{2}$ nanocatalyst via circular coordination-induced growth, with the aim of imbuing EP with high-efficient fire retardant properties [193]. An LDH-DBS@Ni(OH) $)_{2}$ material was designed to 
exploit a spatial-dependent catalytic strategy to improve the interfacial structure between LDH nanosheets and an EP matrix during dynamic charring. The results showed that 3 wt\% LDH-DBS@Ni(OH $)_{2}$ led to an EP matrix with a UL-94 V-0 rating. Xu et al. [191] synthesized a hybrid compound containing MgAl-LDH loaded graphene (RGO-LDH) by a co-precipitation method. An RGO-LDH/CuMoO 4 hybrid was then prepared by introducing $\mathrm{CuMoO}_{4}$ onto the surface of RGO-LDH. Their results illustrated that the pHRR and THR of an EP composite with RGO-LDH/CuMoO ${ }_{4}$ added were decreased significantly. The reason was that the $\mathrm{Cu}_{2} \mathrm{O}$ and $\mathrm{MoO}_{3}$ generated from RGO-LDH/CuMoO${ }_{4}$ in the combustion process helped to increase the yield of char residue and the compactness of the char layer.

3.6. Carbon Skeleton. Graphene is one of the most classic flame retardant C-skeleton two-dimensional nanosheets. In recent years, $\mathrm{g}-\mathrm{C}_{3} \mathrm{~N}_{4}$ and organic frameworks have also been studied in the field of flame retardant polymers.

3.6.1. Graphene. Graphene is a single-layer carbon plate with high thermal conductivity, excellent mechanical strength, and superior electronic conductivity [195-199]. It has been shown that modified graphene has excellent fire resistance even when exposed to flame [200]. In order to obtain improved flame retardant performance, functionalization of graphene or loading of synergistic flame retardants should effectively improve the flame retardant efficiency of graphene.

Various functional treatments or synergistic addition of flame retardants have been performed on graphene surfaces, including the incorporation of $\mathrm{P}, \mathrm{N}$, or Si [201-212]. Hu et al., [62] synthesized a functionalized graphene oxide (FGO) grafted to a hyper-branched flame retardant based on $\mathrm{N}$-aminoethyl piperazine and a phosphonate derivative to reduce the flammability and toxic gas release of polystyrene (PS). The authors attributed the function of this to the homogeneous dispersion of FGO in a PS matrix and enhanced physical barrier effects. Yu et al. [212] successfully prepared functionalized reduced graphene oxide (FRGO) wrapped with $\mathrm{P}-\mathrm{N}$ flame retardants by a one-pot method, and then covalently incorporated them into EP. The glass transition temperature of FRGO/EP nanocomposites remarkably increased by $29.6^{\circ} \mathrm{C}$ under $4 \mathrm{wt} \%$ loading. The pHRR of EP nanocomposites containing 2 wt $\%$ FRGO decreased by $43.0 \%$. Jing et al., [213] reported UL-94 V-0 rating flame retardant PLA composites with a total content of only $3 \mathrm{wt} \%$ using bio-based polyphosphonate (BPPT) and polyethyleneimine-modified graphene oxide (M-GO) as flame retardants. Feng et al., [64] used a "branch-like" strategy with a graphene polymer as the backbone and a flame retardant as the branch to functionalize reduced graphene oxide (RGO) to improve the flame retardant grafting rate and compatibility of RGO in a polymer matrix, and then introduced the resulting GP-DOPO into EP/AgNW composites in situ. Phosphorus-nitrogen co-doped rGO (PN-rGO) was also prepared by a scalable hydrothermal and microwave process to improve the flame retardancy of an EP [214]. Figure 8 shows the schematic illustration of the flame retardation mechanism for EP/PN-rGO. Pethsangave et al. [215] reported that functionalized polyaniline (PANI)- and polypyrrole (PPy)-supported graphene nanocomposites were effective flame retardants. These synthesized nanocomposites showed excellent flame-retardant properties when coated on cotton fabric and wood. Li et al. [216] synthesized a hybrid flame retardant (GO-MD-MP) containing methacryloisobutyl polyhedral oligomeric silsesquioxane (POSSMA), reactive glycidyl methacrylate (GMA), bis-9, 10-dihydro-9-oxa-10-phosphaphenanthrene-10-oxide methacrylate (bisDOPOMA) and its derivative functionalized graphene oxide (GO) via a onestep grafting method. Their results showed that the LOI of EP increased to $31.1 \%$ after adding $4 \mathrm{wt} \%$ GO-MD-MP, and it easily reached a UL- $94 \mathrm{~V}-0$ rating.

Graphene incorporated with metal oxides have also been realized for use as flame retardants [217]. $\mathrm{CeO}_{2} / \mathrm{RGO}$ [218] hybrids and graphene-zinc stannate (G-ZS) [219] hybrids have been synthesized by hydrothermal methods. They can effectively reduce toxic gases released from the combustion process of polymers. Yuan et al. [220] used an ingenious method to decorate $\mathrm{Ni}(\mathrm{OH})_{2}$ nanosheets onto the surface of $\mathrm{GO}$ via the strong affinity of $\mathrm{Ni}^{2+}$ with $\mathrm{NH}_{2}$ groups. Their experiments showed that the addition of functionalized graphene oxide (FGO) reduced the pHRR, THR, and TSP of polypropylene (PP) during combustion. Wang et al. [221] synthesized a series of nitrogenous resorcinol formaldehyde/graphene oxide composite aerogels by using a self-assembly copolymerization strategy. The materials featured with multiple functions, e.g., thermal insulation, ultra light, anti-corrosion, mechanical resilient, high flame-retardant capability.

Graphene has also been incorporated with other inorganic fillers [50, 222-226]. Chen et al. [226] ingeniously prepared a smart fire alarm wallpaper based on ultralong hydroxyapatite nanowires (HNs) and GO thermosensitive sensors. The thermosensitive sensor exhibited a low responsive temperature $\left(126.9^{\circ} \mathrm{C}\right)$, fast response $(2 \mathrm{~s})$, long working time in flame (at least $5 \mathrm{~min}$ ), and could be processed into various shapes, dyed with different colors, and printed with the commercial printer. It had broad application prospects in high-security interior decoration of houses. Nanosilica/graphene oxide (m-SGO) hybrids have been prepared by sol-gel and surface treatment processes on a large number of non-flammable silicas on the surface of graphene oxide [41]. These hybrids significantly improved the flame retardancy, mechanical properties, and thermal stability of an EP, endowing the EP resin with high thermal conductivity, low dielectric loss, and high dielectric constants. Zuo et al. [227] prepared polyimide (PI) composite aerogels with enhanced flame retardancy via an eco-friendly freeze-drying method, followed by a thermal imidization process with graphene and MMT as additives. Guo et al. [228] studied the mechanical and flame retardant properties of four composites, EVA with aluminum hydroxide (ATH), EVA with ATH and $\mathrm{MoS}_{2}$, EVA with ATH and graphene nanoplatelets (GNPs), and EVA with all three components.

3.6.2. $g-C_{3} N_{4}$ and Organic Framework Nanosheets. Analogous to graphene, g- $\mathrm{C}_{3} \mathrm{~N}_{4}$ also has stacked twodimensional structure [229]. Because of its excellent thermal stability, chemical stability, and catalytic performance [230], it has attracted increased attention in the field of flame retardant and smoke suppression. For example, it 
has been used for the improvement of the thermal stability and flame retardancy of polymers. Shi et al. [231] prepared polypropylene-grafted maleic anhydride (PP-g-MA)/g$\mathrm{C}_{3} \mathrm{~N}_{4}$ nanocomposites via a solvent mixing strategy. Their results showed that the $T_{-10}$ and $T_{-50}$ (temperature at $10 \%$ and $50 \%$ weight loss, respectively) of the composites increased by $14.6^{\circ} \mathrm{C}$ and $27.7^{\circ} \mathrm{C}$, respectively. Additionally, a flame retardant CNAPP containing $\mathrm{g}_{-} \mathrm{C}_{3} \mathrm{~N}_{4}$ wrapped ammonium polyphosphate (APP) was prepared and then incorporated into PS [232]. Experimental results show that the main reason for the improvement in flame retardancy of the resulting composites was that the POC and PCN structures formed after combustion significantly improved the stability of the char layer. When the content of g- $\mathrm{C}_{3} \mathrm{~N}_{4}$ in CNAPP was $20 \%$, the best flame retardant effect was obtained (Figures 9 and 10). g- $\mathrm{C}_{3} \mathrm{~N}_{4}$ /organic aluminum diethylhypophosphites (CDAHPI) hybrids have also been synthesized by salification reactions [233]. PS composites were then prepared by a melt blending method. Compared with pure PS, PS/CDAHPI showed additional advantages in terms of inhibiting pyrolysis gas release while reducing HRR and THR of the composite.

Smoke suppression in polymer combustion. The spinel copper cobaltate $\left(\mathrm{CuCo}_{2} \mathrm{O}_{4}\right) / g-\mathrm{C}_{3} \mathrm{~N}_{4}$ (named C- $\mathrm{CuCo}_{2} \mathrm{O}_{4}$ ) nanohybrids were synthesized by hydrothermal method, and then incorporate with TPU by a master batch-melt compounding approach [234]. The number of pyrolysis gas products (including combustible volatiles and $\mathrm{CO}$ ) decreased significantly, while the number of noncombustible gases $\left(\mathrm{CO}_{2}\right)$ increased. The $\mathrm{g}-\mathrm{C}_{3} \mathrm{~N}_{4} /$ organic aluminum hypophosphites hybrid CPDCPAHPI and CBODAHPI [235] were synthesized by esterification and salification reactions, and introduced into PS. The release of flammable aromatic compounds was reduced by introducing these hybrids, which was attributed to the synergy of gas phase action and physical barrier effect in condensed phase. The g- $\mathrm{C}_{3} \mathrm{~N}_{4} /$ carbon sphere/Cu (CSACS-C) nanohybrid [236] were prepared by metal ions-induced gel reaction as green template, and the amount of pyrolysis gaseous products; generation and pHRR of TPU/CSACS-C composites were significantly reduced.

Recently, organic frameworks, including covalent organic frameworks and metal organic frameworks, have also begun to be used as flame retardants in polymers [237-239]. Hou et al. [237] synthesized iron-based and cobalt-based metalorganic frameworks (MOFs) by solvothermal method and prepared PS/MOF composites. Compared with pure PS, the $\mathrm{pHRR}$ of PS/Fe-MOF and PS/Co-MOF decreased by $14 \%$ and $28 \%$, respectively, indicating that MOF has flame retardant effect in polymer. Subsequently, DOPO was used to modify Co-MOF and introduced to PLA to improve the fire safety and mechanical properties of the composites [238]. Mu et al. [239] prepared the original phosphorus-containing flame retardant wrapped covalent organic frameworks (FCOFs) nanosheets and introduced it to EP by in-situ polymerization, which had a positive impact on the flame retardancy, toxic volatiles and the quality of char residue of the composites. Recently, the flame retardant properties of various two-dimensional materials/polymers have been extensively studied. The results are listed in Table 2.

\section{Conclusion}

Clarifying the special properties of various two-dimensional nanomaterials is pivotal for being able to fully exploit their flame-retardant properties. With increased awareness of the structure and properties of two-dimensional nanomaterials, researchers will be able to realize the potential of two-dimensional nanomaterials for fulfilling required flame-retardant effects under low load conditions. Based on the specific properties of different two-dimensional nanomaterials, they can be reasonably used as additives or reactive components in the design of polymer flame-retardant materials. With additional research, two-dimensional nanomaterials/polymers will be more suitable for specific applications. Although two-dimensional nanomaterials are widely used to prepare fireproofing materials in the laboratory because of their high efficiency and environmental friendliness, many challenges still remain. First is the challenge of the large-scale application of two-dimensional nanomaterials. New two-dimensional nanomaterials, including g- $\mathrm{C}_{3} \mathrm{~N}_{4}$ and black phosphorus, have not been prepared at industrial as of yet. Moreover, the uniform dispersion of many two-dimensional nanomaterials in a polymer matrix depends on their efficient exfoliation and surface modification. The application of hydrophobic technology of two-dimensional nanomaterials in industry is promising. Second is finding suitable flame retardant applications for two-dimensional nanomaterials. In specific applications, polymer materials not only need to meet flame retardant requirements, but also need to face meet requirements for heat dissipation, dielectric properties, etc. In some special cases, appropriate multifunctional nanosheets can be designed to meet specific design challenges according to the molecular components and structure of the two-dimensional nanomaterial. For example, in highly integrated small electronic devices, h-BN nanosheets are a reasonable choice.

The authors are confident that the above-mentioned challenges will be gradually overcome through the continuous development and innovation of two-dimensional nanomaterials due to their intrinsic advantages over other materials. The thorough survey of the current literature presented here offers useful information for realizing the potential of two-dimensional nanomaterials/polymer and should help in guiding the design of novel high-performance flame-retardant composites.

\section{Conflicts of Interest}

The authors declare that they have no conflicts of interest.

\section{Acknowledgments}

Financial support from the National Key R\&D Program of China Grant No. 2016YFB0302303 and the Guangdong YangFan Innovative \& Entrepreneurial Research Team Program (Project No. 201633002) is gratefully acknowledged.

\section{References}

[1] X. Qiu, Z. Li, X. Li, and Z. Zhang, "Flame retardant coatings prepared using layer by layer assembly: a review," Chemical Engineering Journal, vol. 334, pp. 108-122, 2018. 
[2] Department of Emergency Management Fire and Rescue Bureau, "Data interpretation of fire and emergency," 2019, http://www.119.gov.cn/xiaofang/hztj/36306.htm.

[3] M. M. Velencoso, A. Battig, J. C. Markwart, B. Schartel, and F. R. Wurm, "Molecular firefighting-how modern phosphorus chemistry can help solve the challenge of flame retardancy," Angewandte Chemie International Edition, vol. 57, no. 33, pp. 10450-10467, 2018.

[4] Y. Li, C. Kuan, S. Hsu et al., "Preparation, thermal stability and flame-retardant properties of halogen-free polypropylene composites," Journal of High Performance Polymers, vol. 24, pp. 478-487, 2012.

[5] L. Liu, J. L. Liu, X. L. Chen, and C. M. Jiao, "Synergistic effect between hollow glass beads and aluminium hydroxide in flame retardant EVA composites," Plastics, Rubber and Composites, vol. 43, pp. 77-81, 2014.

[6] Z. Wang, Y. Liu, and Q. Wang, "Flame retardant polyoxymethylene with aluminium hydroxide/melamine/ novolac resin synergistic system," Polymer Degradation and Stability, vol. 95, no. 6, pp. 945-954, 2010.

[7] H. Yan, J. Wei, B. Yin, and M. Yang, "Effect of the surface modification of ammonium polyphosphate on the structure and property of melamine-formaldehyde resin microencapsulated ammonium polyphosphate and polypropylene flame retardant composites," Polymer Bulltin, vol. 72, no. 11, pp. 2725-2737, 2015.

[8] K. Wu, M. Shen, and Y. Hu, "Synthesis of a novel intumescent flame retardant and its flame retardancy in polypropylene," Journal of Polymer Research, vol. 18, no. 3, pp. 425-433, 2011.

[9] S. Chiu, C. Wu, H. Lee, J. Gu, and M. Suen, "Synthesis and characterisation of novel flame retardant polyurethanes containing designed phosphorus units," Journal of Polymer Research, vol. 23, no. 10, p. 205, 2016.

[10] U. Braun, A. I. Balabanovich, B. Schartel et al., "Influence of the oxidation state of phosphorus on the decomposition and fire behaviour of flame-retarded epoxy resin composites," Polymer, vol. 47, no. 26, pp. 8495-8508, 2006.

[11] C. Kizilkaya, Y. Mülazim, M. Vezir Kahraman, N. Kayaman Apohan, and A. Güngör, "Synthesis and characterization of polyimide/hexagonal boron nitride composite," Journal of Applied Polymer Science, vol. 124, no. 1, pp. 706-712, 2012.

[12] A. Yaras, E. Er, H. Çelikkan, A. Disli, and A. Alicilar, "Cellulosic tent fabric coated with boron nitride nanosheets," Journal of Industrial Textiles, vol. 45, no. 6, pp. 1689-1700, 2015.

[13] J. Liu, R. G. Kutty, Q. Zheng, V. Eswariah, S. Sreejith, and Z. Liu, "Hexagonal boron nitride nanosheets as high-performance binder-free fire-resistant wood coatings," Small, vol. 13, no. 2, Article ID 1602456, 2017.

[14] F. Chu, D. Zhang, Y. Hou et al., "Construction of hierarchical natural fabric surface structure based on two-dimensional boron nitride nanosheets and its application for preparing biobased toughened unsaturated polyester resin composites," ACS Applied Materials \& Interfaces, vol. 10, no. 46, pp. 4016840179, 2018.

[15] Y.-R. Zhi, B. Yu, A. C. Y. Yuen et al., "Surface manipulation of thermal-exfoliated hexagonal boron nitride with polyaniline for improving thermal stability and fire safety performance of polymeric materials," ACS Omega, vol. 3, lpp. 14942-14952, 2018.

[16] J. Wang, D. Zhang, Y. Zhang et al., "Construction of multifunctional boron nitride nanosheet towards reducing toxic volatiles ( $\mathrm{CO}$ and $\mathrm{HCN}$ ) generation and fire hazard of thermoplastic polyurethane," Journal of Hazardous Materials, vol. 362, pp. 482-494, 2019.

[17] K. Zhou, S. Jiang, Y. Shi et al., "Multigram-scale fabrication of organic modified $\mathrm{MoS}_{2}$ nanosheets dispersed in polystyrene with improved thermal stability, fire resistance, and smoke suppression properties," Royal Society of Chemistry Advances, vol. 4, no. 76, pp. 40170-40180, 2014.

[18] D. Wang, L. Song, K. Zhou, X. Yu, Y. Hu, and J. Wang, "Anomalous nano-barrier effects of ultrathin molybdenum disulfide nanosheets for improving the flame retardance of polymer nanocomposites," Journal of Materials Chemistry A, vol. 3, no. 27, pp. 14307-14317, 2015.

[19] K. Zhou, J. Liu, Y. Shi et al., "MoS 2 nanolayers grown on carbon nanotubes: an advanced reinforcement for epoxy composites," A. C. S. Applied Materials \& Interfaces, vol. 7, no. 11, pp. 60706081, 2015.

[20] K. Zhou, J. Liu, Z. Gui, Y. Hu, and S. Jiang, “The influence of melamine phosphate modified $\mathrm{MoS}_{2}$ on the thermal and flammability of poly(butylene succinate) composites," Polymers For Advanced Technologies, vol. 27, no. 14, pp. 13971400, 2016.

[21] X. Ren, Y. Mei, P. Lian et al., "A novel application of phosphorene as a flame retardant," Polymers-Basel, vol. 10, no. 3, p. 227, 2018.

[22] W. Zhou, T. Jia, H. Shi, D. Yu, W. Hong, and X. Chen, "Conjugated polymer dots/graphitic carbon nitride nanosheet heterojunctions for metal-free hydrogen evolution photocatalysis," Journal of Materials Chemistry A, vol. 7, no. 1, pp. 303-311, 2019.

[23] L. Sun, W. Hong, J. Liu et al., "Cross-linked graphitic carbon nitride with photonic crystal structure for efficient visiblelight-driven photocatalysis," A. C. S. Applied Materials \& Interfaces, vol. 9, no. 51, pp. 44503-44511, 2017.

[24] A. K. Chaudhari, S. S. Nagarkar, B. Joarder, and S. K. Ghosh, "A continuous $\pi$-stacked starfish array of two-dimensional luminescent MOF for detection of nitro explosives," Crystal Growth \& Design, vol. 13, no. 8, pp. 3716-3721, 2013.

[25] Q. Weng, B. Wang, X. Wang et al., "Highly water-soluble, porous, and biocompatible boron nitrides for anticancer drug delivery," ACS Nano Materials, vol. 8, no. 6, pp. 6123-6130, 2014.

[26] F. Ahmed, Y. D. Kim, M. S. Choi et al., "High electric field carrier transport and power dissipation in multilayer black phosphorus field effect transistor with dielectric engineering," Advanced Functional Materials, vol. 27, no. 4, Article ID 1604025, 2017.

[27] L. Yang, S. Wang, J. Mao et al., "Hierarchical $\mathrm{MoS}_{2} /$ polyaniline nanowires with excellent electrochemical performance for lithium-ion batteries," Advanced Materials, vol. 25, no. 8, pp. 1180-1184, 2013.

[28] X. Zeng, D. T. McCarthy, A. Deletic, and X. Zhang, "Silver/ reduced graphene oxide hydrogel as novel bactericidal filter for point-of-use water disinfection," Advanced Functional Materials, vol. 25, no. 27, pp. 4344-4351, 2015.

[29] L. Cseri, J. Baugh, A. Alabi et al., "Graphene oxidepolybenzimidazolium nanocomposite anion exchange membranes for electrodialysis," Journal of Materials Chemistry A, vol. 6, no. 48, pp. 24728-24739, 2018.

[30] K. Bhunia, S. Khilari, D. Pradhan, "Monodispersed PtPdNi trimetallic nanoparticles-integrated reduced graphene oxide 
hybrid platform for direct alcohol fuel cell," A. C. S. Sustain Chemistry \& Enginering, vol. 6, no. 6, pp. 7769-7778, 2018.

[31] F. Fei, L. Cseri, G. Szekely, C. F. Blanford, "Robust covalently cross-linked polybenzimidazole/graphene oxide membranes for high-flux organic solvent nanofiltration," A. C. S. Applied Materials \& Interfaces, vol. 10, no. 8, pp. 16140-16147, 2018.

[32] K. Pan, Y. Fan, T. Leng et al., "Sustainable production of highly conductive multilayer graphene ink for wireless connectivity and IoT applications," Nature Communications, p. 5197, 2018.

[33] R. Wang, G. Xia, W. Zhong et al., "Direct transformation of lignin into fluorescence-switchable graphene quantum dots and their application in ultrasensitive profiling of a physiological oxidant," Green Chemistry, vol. 21, no. 12, pp. 3343-3352, 2019.

[34] M. Razali, J. F. Kim, M. Attfield et al., "Sustainable wastewater treatment and recycling in membrane manufacturing," Green Chemistry, vol. 17, no. 12, pp. 5196-5205, 2015.

[35] X. Dong, L. Wang, D. Wang, C. Li, and J. Jin, "Layer-by-layer engineered co-al hydroxide nanosheets/graphene multilayer films as flexible electrode for supercapacitor," Langmuir, vol. 28, no. 1, pp. 293-298, 2011.

[36] B. Lin, C. Ding, B. Xu, Z. Chen, and Y. Chen, "Preparation and characterization of polythiophene/molybdenum disulfide intercalation material," Materials Research Bulletin, vol. 44, no. 4, pp. 719-723, 2009.

[37] X. Wang and P. Wu, "Preparation of highly thermally conductive polymer composite at low filler content via a self-assembly process between polystyrene microspheres and boron nitride nanosheets," ACS Applied Materials \& Interfaces, vol. 9, no. 23, pp. 19934-19944, 2016.

[38] H. Yan and Y. Huang, "Polymer composites of carbon nitride and poly(3-hexylthiophene) to achieve enhanced hydrogen production from water under visible light," Chemical Communications, vol. 47, no. 14, pp. 4168-4170, 2011.

[39] K. Zhou, R. Gao, and X. Qian, "Self-assembly of exfoliated molybdenum disulfide $\left(\mathrm{MoS}_{2}\right)$ nanosheets and layered double hydroxide (LDH): towards reducing fire hazards of epoxy," Journal of Hazardous Materials, vol. 338, pp. 343-355, 2017.

[40] W. Wang, H. Pan, Y. Shi et al., "Fabrication of LDH nanosheets on $\beta-\mathrm{FeOOH}$ rods and applications for improving the fire safety of epoxy resin," Composites Part A: Applied Science and Manufacturing, vol. 80, pp. 259-269, 2016.

[41] R. Wang, D. Zhuo, Z. Weng et al., "A novel nanosilica/ graphene oxide hybrid and its flame retarding epoxy resin with simultaneously improved mechanical, thermal conductivity, and dielectric properties," Journal of Materials Chemistry A, vol. 3, no. 18, pp. 9826-9836, 2015.

[42] W. Cai, D. Zhang, B. Wang et al., "Scalable one-step synthesis of hydroxylated boron nitride nanosheets for obtaining multifunctional polyvinyl alcohol nanocomposite films: multi-azimuth properties improvement," Composites Science and Technology, vol. 168, pp. 74-80, 2018.

[43] Y. Shi, S. Jiang, K. Zhou et al., "Influence of g- $\mathrm{C}_{3} \mathrm{~N}_{4}$ nanosheets on thermal stability and mechanical properties of biopolymer electrolyte nanocomposite films: a novel investigation," ACS Applied Materials \& Interfaces, vol. 6, no. 1, pp. 429-437, 2013.

[44] P. K. Kaul, A. J. Samson, G. T. Selvan, I. Enoch, and P. M. Selvakumar, "Synergistic effect of LDH in the presence of organophosphate on thermal and flammable properties of an epoxy nanocomposite," Applied Clay Science, vol. 135, pp. 234-243, 2017.
[45] S. Zhang, X. Liu, X. Jin, H. Li, J. Sun, and X. Gu, “The novel application of chitosan: effects of cross-linked chitosan on the fire performance of thermoplastic polyurethane," Carbohydrate Polymers, vol. 189, pp. 313-321, 2018.

[46] C. Zhi, Y. Bando, C. Tang, H. Kuwahara, and D. Golberg, "Large-scale fabrication of boron nitride nanosheets and their utilization in polymeric composites with improved thermal and mechanical properties," Advanced Materials, vol. 21, no. 28, pp. 2889-2893, 2009.

[47] Z. Lin, A. McCreary, N. Briggs et al., "2D materials advances: from large scale synthesis and controlled heterostructures to improved characterization techniques, defects and applications," 2D Materials, vol. 3, no. 4, Article ID 042001, 2016.

[48] S. I. Kudryashov, L. V. Nguyen, D. A. Kirilenko et al., "Largescale laser fabrication of antifouling silicon-surface nanosheet arrays via nanoplasmonic ablative self-organization in liquid cs2 tracked by a sulfur dopant," ACS Applied Nano Materials, vol. 1, no. 6, pp. 2461-2468, 2018.

[49] Y. Yao, Z. Lin, Z. Li, X. Song, K. Moon, and C. Wong, "Largescale production of two-dimensional nanosheets," Journal of Materials Chemistry, vol. 22, no. 27, pp. 13494-13499, 2012.

[50] K. Zhou, Z. Gui, and Y. Hu, "The influence of graphene based smoke suppression agents on reduced fire hazards of polystyrene composites," Composites Part A, vol. 80, pp. 217227, 2016.

[51] W. Cai, W. Guo, Y. Pan et al., "Polydopamine-bridged synthesis of ternaryh-BN@PDA@SnO ${ }_{2}$ as nanoenhancers for flame retardant and smoke suppression of epoxy composites," Composites Part A, vol. 111, pp. 94-105, 2018.

[52] B. Radisavljevic, A. Radenovic, J. Brivio, V. Giacometti, and A. Kis, "Single-layer $\mathrm{MoS}_{2}$ transistors," Nature Nanotechnology, vol. 6, pp. 147-150, 2011.

[53] M. Pica, "Zirconium phosphate catalysts in the XXI century: state of the art from 2010 to date," Catalysts., vol. 7, p. 190, 2017.

[54] M. Xu, T. Liang, M. Shi, and H. Chen, "Graphene-like twodimensional materials," Chemical Reviews, vol. 113, no. 5, pp. 3766-3798, 2013.

[55] C. Swearingen, S. Macha, and A. Fitch, "Leashed ferrocenes at clay surfaces: potential applications for environmental catalysis," Journal of Molecular Catalysts A-Chemistry, vol. 199, no. 1-2, pp. 149-160, 2003.

[56] S. Qiu, Y. Zhou, X. Zhou et al., "Air-stable polyphosphazenefunctionalized few-layer black phosphorene for flame retardancy of epoxy resins," Small, vol. 15, Article ID 1805175, 2019.

[57] L. Yan, Y. B. Zheng, F. Zhao et al., "Chemistry and physics of a single atomic layer: strategies and challenges for functionalization of graphene and graphene-based materials," Chemical Society Reviews, vol. 41, no. 1, pp. 97-114, 2012.

[58] C. Hobbs, "Recent advances in bio-based flame retardant additives for synthetic polymeric materials," Polymers-Basel, vol. 11, no. 2, p. 224, 2019.

[59] L Xu, C. Lei, R. Xu, X. Zhang, and F. Zhang, "Functionalization of $\alpha$-zirconium phosphate by polyphosphazene and its effect on the flame retardance of an intumescent flame retardant polypropylene system," RSC Advances, vol. 6, no. 81, pp. 77545-77552, 2016.

[60] E. N. Kalali, X. Wang, and D. Wang, "Functionalized layered double hydroxide-based epoxy nanocomposites with improved 
flame retardancy and mechanical properties," Journal of Materials Chemistry A, vol. 3, no. 13, pp. 6819-6826, 2015.

[61] Y. Shi, Z. Long, B. Yu et al., "Tunable thermal, flame retardant and toxic effluent suppression properties of polystyrene based on alternating graphitic carbon nitride and multi-walled carbon nanotubes," Journal of Materials Chemistry A, vol. 3, no. 33, pp. 17064-17073, 2015.

[62] W. Hu, B. Yu, S. Jiang, L. Song, Y. Hu, and B. Wang, "Hyperbranched polymer grafting graphene oxide as an effective flame retardant and smoke suppressant for polystyrene," Journal of Hazardous Materials, vol. 300, pp. 58-66, 2015.

[63] H. Xie, X. Lai, H. Li, and X. Zeng, "Fabrication of ZrP nanosheet decorated macromolecular charring agent and its efficient synergism with ammonium polyphosphate in flameretarding polypropylene," Composites Part A: Applied Science and Manufacturing, vol. 105, pp. 223-234, 2018.

[64] Y. Feng, X. Li, X. Zhao et al., "Synergetic improvement in thermal conductivity and flame retardancy of epoxy/silver nanowires composites by incorporating "branch-like" flameretardant functionalized graphene," ACS Applied Materials \& Interfaces, vol. 10, no. 25, pp. 21628-21641, 2018.

[65] X. Wang, E. N. Kalali, and D. Wang, "Renewable cardanolbased surfactant modified layered double hydroxide as a flame retardant for epoxy resin," A. C. S. Sustain Chemistry \& Engineering, vol. 3, no. 12, pp. 3281-3290, 2015.

[66] W. Xu, B. Zhang, B. Xu, and A. Li, “The flame retardancy and smoke suppression effect of heptaheptamolybdate modified reduced graphene oxide/layered double hydroxide hybrids on polyurethane elastomer," Composites Part A: Applied Science and Manufacturing, vol. 91, no. Part 1, pp. 30-40, 2016.

[67] D. Yang, Y. Hu, H. Li, L. Song, H. Xu, and B. Li, "Synergistic flame retardant effect of $\alpha$-zirconium phosphate in low-density polyethylene/ethylene-vinyl acetate/aluminum hydroxide hybrids," Journal of Thermal Analysis and Calorimetry, vol. 119, no. 1, pp. 619-624, 2015.

[68] X. Ren, Y. Mei, P. Lian et al., "Fabrication and application of black phosphorene/graphene composite material as a flame retardant," Polymers-Basel, vol. 11, no. 2, p. 193, 2019.

[69] K. Wenelska, K. Ma Lana, and E. Mijowska, "Study on the flammability, thermal stability and diffusivity of polyethylene nanocomposites containing few layered tungsten disulfide (WS 2) functionalized with metal oxides," RSC Advances, vol. 8, no. 23, pp. 12999-13007, 2018.

[70] A. Díez-Pascual and M. Naffakh, "Inorganic nanoparticlemodified poly(phenylene sulphide)/carbon fiber laminates: thermomechanical behaviour," Materials, vol. 6, no. 8, pp. 3171-3193, 2013.

[71] K. Wenelska and E. Mijowska, "Preparation, thermal conductivity, and thermal stability of flame retardant polyethylene with exfoliated $\mathrm{MoS}_{2} / \mathrm{M}_{\mathrm{x}} \mathrm{O}_{\mathrm{y}}$ ” $\mathrm{New}$ Journal of Chemistry, vol. 41, no. 22, pp. 13287-13292, 2017.

[72] L. Yang, A. Mukhopadhyay, Y. Jiao et al., "Ultralight, highly thermally insulating and fire resistant aerogel by encapsulating cellulose nanofibers with two-dimensional $\mathrm{MoS}_{2}$," Nanoscale, vol. 9, no. 32, pp. 11452-11462, 2017.

[73] X. Zhou, S. Qiu, W. Xing, C. S. R. Gangireddy, Z. Gui, and Y. Hu, "Hierarchical polyphosphazene@molybdenum disulfide hybrid structure for enhancing the flame retardancy and mechanical property of epoxy resins," $A$. C. S. Applied Materials \& Interfaces, vol. 9, no. 34, pp. 29147-29156, 2017.
[74] D. Wang, P. Wen, J. Wang, L. Song, and Y. Hu, "The effect of defect-rich molybdenum disulfide nanosheets with phosphorus, nitrogen and silicon elements on mechanical, thermal, and fire behaviors of unsaturated polyester composites," Chemical Engineering Journal, vol. 313, pp. 238249, 2017.

[75] K. Zhou, G. Tang, R. Gao, and H. Guo, "Constructing hierarchical polymer@ $\mathrm{MoS}_{2}$ core-shell structures for regulating thermal and fire safety properties of polystyrene nanocomposites," Composites Part A: Applied Science and Manufacturing, vol. 107, pp. 144-154, 2018.

[76] K. Zhou, R. Gao, Z. Gui, and Y. Hu, "The effective reinforcements of functionalized $\mathrm{MoS}_{2}$ nanosheets in polymer hybrid composites by sol-gel technique," Composites Part A: Applied Science and Manufacturing, vol. 94, pp. 1-9, 2017.

[77] W. Cai, J. Zhan, X. Feng et al., "Facile construction of flameretardant-wrapped molybdenum disulfide nanosheets for properties enhancement of thermoplastic polyurethane," Industrial \& Engineering Chemistry Research, vol. 56, no. 25, pp. 7229-7238, 2017.

[78] K. Zhou, G. Tang, S. Jiang, Z. Gui, and Y. Hu, "Combination effect of $\mathrm{MoS}_{2}$ with aluminum hypophosphite in flame retardant ethylene-vinyl acetate composites," RSC Advances, vol. 6, no. 44, pp. 37672-37680, 2016.

[79] X. Feng, B. Wang, X. Wang et al., "Molybdenum disulfide nanosheets as barrier enhancing nanofillers in thermal decomposition of polypropylene composites," Chemical Engineering Journal, vol. 295, pp. 278-287, 2016.

[80] X. Yang, N. Meng, Y. Zhu, Y. Zhou, W. Nie, and P. Chen, "Greatly improved mechanical and thermal properties of chitosan by carboxyl-functionalized $\mathrm{MoS}_{2}$ nanosheets," Journal of Materials Science, vol. 51, no. 3, pp. 1344-1353, 2016.

[81] K. Zhou, Z. Gui, and Y. Hu, "Synthesis and characterization of $\mathrm{Cu}-\mathrm{MoS}_{2}$ hybrids and their influence on the thermal behavior of polyvinyl chloride composites," RSC Advances, vol. 6, no. 91, pp. 8877-88712, 2016.

[82] K. Zhou, J. Liu, W. Zeng, Y. Hu, and Z. Gui, "In situ synthesis, morphology, and fundamental properties of polymer/MoS nanocomposites," Composites Science and Technology, vol. 107, pp. 120-128, 2015.

[83] Y. Zhong, M. Li, L. Zhang, X. Zhang, S. Zhu, and W. Wu, "Adding the combination of CNTs and $\mathrm{MoS}_{2}$ into halogenfree flame retarding TPEE with enhanced the anti-dripping behavior and char forming properties," Thermochimica Acta, vol. 613, pp. 87-93, 2015.

[84] K. Zhou, Q. Zhang, J. Liu et al., "Synergetic effect of ferrocene and $\mathrm{MoS}_{2}$ in polystyrene composites with enhanced thermal stability, flame retardant and smoke suppression properties," RSC Advances, vol. 4, no. 26, p. 13205, 2014.

[85] S. Jiang, G. Tang, Z. Bai, Y. Wang, Y. Hu, and L. Song, "Surface functionalization of $\mathrm{MoS}_{2}$ with POSS for enhancing thermal, flame-retardant and mechanical properties in PVA composites," RSC Advances, vol. 4, no. 7, pp. 3253-3262, 2014.

[86] K. Zhou, R. Gao, and X. Qian, "Self-assembly of exfoliated molybdenum disulfide $\left(\mathrm{MoS}_{2}\right)$ nanosheets and layered double hydroxide (LDH): towards reducing fire hazards of epoxy," Journal of Hazardous Materials, vol. 338, pp. 343-355, 2017.

[87] K. Zhou, C. Liu, and R. Gao, "Polyaniline: a novel bridge to reduce the fire hazards of epoxy composites," Composites Part A: Applied Science and Manufacturing, vol. 112, pp. 432-443, 2018. 
[88] S. Qiu, Y. Hu, Y. Shi et al., "In situ growth of polyphosphazene particles on molybdenum disulfide nanosheets for flame retardant and friction application," Composites Part A: Applied Science and Manufacturing, vol. 114, pp. 407-417, 2018.

[89] A. Li, W. Xu, G. Wang, and X. Wang, "Novel strategy for molybdenum disulfide nanosheets grown on titanate nanotubes for enhancing the flame retardancy and smoke suppression of epoxy resin," Journal of Applied Polymer Science, vol. 135, no. 15, p. 46064, 2018.

[90] H. Pan, Q. Shen, Z. Zhang, B. Yu, and Y. Lu, "MoS -filled coating on flexible polyurethane foam via layer-by-layer assembly technique: flame-retardant and smoke suppression properties," Journal of Materials Science, vol. 53, no. 12, pp. 9340-9349, 2018.

[91] X. Feng, X. Wang, W. Cai, N. Hong, Y. Hu, and K. M. Liew, "Integrated effect of supramolecular self-assembled sandwichlike melamine cyanurate/ $\mathrm{MoS}_{2}$ hybrid sheets on reducing fire hazards of polyamide 6 composites," Journal of Hazardous Materials, vol. 320, pp. 252-264, 2016.

[92] A. M. Díez-Pascual and M. Naffakh, "Mechanical and thermal behaviour of isotactic polypropylene reinforced with inorganic fullerene-like $\mathrm{WS}_{2}$ nanoparticles: Effect of filler loading and temperature," Materials Chemistry and Physics, vol. 141, no. 2-3, pp. 979-989, 2013.

[93] D. Yang, Y. Hu, H. Li et al., "Flammability and carbonization of high-impact polystyrene/ $\alpha$-zirconium phosphate nanocomposites," Iranian Polymer Journal, vol. 24, no. 12, pp. 1069-1075, 2015.

[94] Y. Du, F. Deng, X. Jiang et al., "Preparation and performance of lipophilic $\alpha$-zirconium phosphate with high thermal stability and its application in thermal-plastic polymers," Progress in Natural Science-Materials International, vol. 25, no. 5, pp. 503511, 2015.

[95] Y. Pan, H. Pan, B. Yuan et al., "Construction of organicinorganic hybrid nano-coatings containing $\alpha$-zirconium phosphate with high efficiency for reducing fire hazards of flexible polyurethane foam," Materials Chemistry and Physics, vol. 163, pp. 107-115, 2015.

[96] Y. Zhang, X. Zeng, H. Li, X. Lai, Y. Guo, and R. Zheng, "Zirconium phosphate functionalized by hindered amine: a new strategy for effectively enhancing the flame retardancy of addition-cure liquid silicone rubber," Materials Letters, vol. 174, pp. 230-233, 2016.

[97] F. Fang, B. Tong, T. Du et al., "Unique nanobrick wall nanocoating for flame-retardant cotton fabric via layer-bylayer assembly technique," Cellulose, vol. 23, no. 5, pp. 33413354, 2016.

[98] C. Zhao, P. Li, D. He, Y. Li, F. Lei, and H. Sue, "Flame retardation behavior of polybenzoxazine/ $\alpha$-ZrP nanocomposites," $R S C$ Advances, vol. 6, no. 77, pp. 73485-73495, 2016.

[99] L. C. Hatanaka, A. Diaz, Q. Wang, Z. Cheng, and M. S. Mannan, "Thermal stability of optically transparent alpha-zirconium phosphate/poly(methyl methacrylate) nanocomposites with high particle loading," Polymers \& Polymer Composites, vol. 25, no. 4, pp. 267-272, 2017.

[100] Y. Xiao, J. Xu, S. Huang, and H. Deng, "Effects of $\alpha$-ZrP on crystallinity and flame-retardant behaviors of PA6/ MCA composites," International Journal of Polymer Science, vol. 2017, pp. 1-12, Article ID 6034741, 2017.

[101] L. Xu, C. Lei, R. Xu, X. Zhang, and F. Zhang, "Synergistic effect on flame retardancy and thermal behavior of polycarbonate filled with $\alpha$-zirconium phosphate@gel-silica," Journal of Applied Polymer Science, vol. 134, no. 19, 2017.

[102] H. Xiang, L. Li, W. Chen, S. Yu, B. Sun, and M. Zhu, "Flame retardancy of polyamide 6 hybrid fibers: combined effects of $\alpha$-zirconium phosphate and ammonium sulfamate," Progress in Natural Science-Materials International, vol. 27, no. 5, pp. 369-373, 2017.

[103] Y. Ding, Y. Luo, F. Xue, Z. Jia, and D. Jia, "Synthesis of phosphazene derivative modified $\alpha$-zirconium phosphate and its effect on the flame retardancy and mechanical properties of silicone rubber in combination with ammonium polyphosphate," Acta Polymer Sinica, vol. 11, pp. 1796-1805, 2017.

[104] J. Yue, C. Zhao, Y. Dai, H. Li, and Y. Li, "Catalytic effect of exfoliated zirconium phosphate on the curing behavior of benzoxazine," Thermochimica Acta, vol. 650, pp. 18-25, 2017.

[105] K. Li, H. Lei, X. Zeng, H. Li, X. Lai, and S. Chai, "Preparation of a flame retardant phosphorus-containing polyacrylate $/ \alpha$ zirconium phosphate nanocomposite through in situ emulsion polymerization," RSC Advances, vol. 7, no. 78, pp. 4929049298, 2017.

[106] H. Yan, L. Zhao, Z. Fang, and H. Wang, "Construction of multilayer coatings for flame retardancy of ramie fabric using layer-by-layer assembly," Journal of Applied Polymer Science, vol. 134, no. 48, p. 45556, 2017.

[107] Y. Zhang, X. Zeng, X. Lai, and H. Li, "Preparation of functionalized zirconium phosphate and its effect on the flame retardancy of silicone rubber," RSC Advances, vol. 8, no. 1, pp. 111-121, 2018.

[108] B. Xu, W. Xu, Y. Liu et al., "Surface modification of $\alpha$-zirconium phosphate by zeolitic imidazolate frameworks- 8 and its effect on improving the fire safety of polyurethane elastomer," Polymers for Advanced Technologies, vol. 29, no. 11, pp. 28162826, 2018.

[109] H. Xie, X. Lai, H. Li, and X. Zeng, "Remarkably improving the fire-safety of polypropylene by synergism of functionalized ZrP nanosheet and N-alkoxy hindered amine," Applied Clay Science, vol. 166, pp. 61-73, 2018.

[110] L. Xu, C. Lei, R. Xu, X. Zhang, and J. Xu, "Intumescent flame retardant of polypropylene system with enhanced thermal properties and flame retardancy based on $\alpha$-zirconium phosphate composite particles," Polymer Bulletin, vol. 75, no. 6, pp. 2707-2727, 2018.

[111] S. Yu, H. Xiang, J. Zhou, Z. Zhou, and M. Zhu, "The synergistic effect of organic phosphorous/ $\alpha$-zirconium phosphate on flame-retardant poly(lactic acid) fiber," Fibers and Polymers, vol. 19, no. 4, pp. 812-820, 2018.

[112] N. Pérez, X. Qi, S. Nie, P. Acuña, M. Chen, and D. Wang, "Flame retardant polypropylene composites with low densities," Materials, vol. 12, no. 1, p. 152, 2019.

[113] L. Xu, C. Lei, R. Xu, X. Zhang, and F. Zhang, "Hybridization of $\alpha$-zirconium phosphate with hexachlorocyclotriphosphazene and its application in the flame retardant poly(vinyl alcohol) composites," Polymer Degradation and Stability, vol. 133, pp. 378-388, 2016.

[114] X. Fu, X. Wang, W. Xing, P. Zhang, L. Song, and Y. Hu, “Twodimensional cardanol-derived zirconium phosphate hybrid as flame retardant and smoke suppressant for epoxy resin," Polymer Degradation and Stability, vol. 151, pp. 172-180, 2018.

[115] S. Qiu, Y. Zhou, X. Zhou et al., "Air-stable polyphosphazenefunctionalized few-layer black phosphorene for flame 
retardancy of epoxy resins," Small, vol. 15, no. 10, Article ID 1805175, 2019.

[116] K. Zhou, Z. Gui, and Y. Hu, "Ultrathin 2D VOPO4 nanosheets: a novel reinforcing agent in polymeric composites," RSC Advances, vol. 6, no. 102, pp. 100344-100351, 2016.

[117] K. Zhou and R. Gao, "The influence of a novel two dimensional graphene-like nanomaterial on thermal stability and flammability of polystyrene," Journal of Colloid and Interface Science, vol. 500, pp. 164-171, 2017.

[118] X. Li, Y. Feng, C. Chen et al., "Highly thermally conductive flame retardant epoxy nanocomposites with multifunctional ionic liquid flame retardant-functionalized boron nitride nanosheets," Journal of Materials Chemistry A, vol. 6, no. 41, pp. 20500-20512, 2018.

[119] S. Qiu, Y. Hou, W. Xing et al., "Self-assembled supermolecular aggregate supported on boron nitride nanoplatelets for flame retardant and friction application," Chemical Engineering Journal, vol. 349, pp. 223-234, 2018.

[120] Y. Dong and G. Wang, "Influence of nano-boron nitride on fire protection of waterborne fire-resistive coatings," Journal of Coatings Technology and Research, vol. 11, no. 2, pp. 265-272, 2014.

[121] B. Yu, W. Xing, W. Guo et al., "Thermal exfoliation of hexagonal boron nitride for effective enhancements on thermal stability, flame retardancy and smoke suppression of epoxy resin nanocomposites via sol-gel process," Journal of Materials Chemistry A, vol. 4, no. 19, pp. 733-734, 2016.

[122] D. Liu, M. Zhang, L. He, Y. Chen, and W. Lei, "Layer-bylayer assembly fabrication of porous boron nitride coated multifunctional materials for water cleaning," Advanced Materials Interfaces, vol. 4, no. 16, Article ID 1700392, 2017.

[123] W. Cai, N. Hong, X. Feng et al., "A facile strategy to simultaneously exfoliate and functionalize boron nitride nanosheets via Lewis acid-base interaction," Chemical Engineering Journal, vol. 330, pp. 309-321, 2017.

[124] Y. Zhong, L. Zhang, A. Fischer, L. Wang, D. Drummer, and $\mathrm{W}$. Wu, "The effect of hBN on the flame retardancy and thermal stability of P-N flame retardant PA6," Journal of Macromolecular Science, Part A, vol. 55, no. 1, pp. 17-23, 2018.

[125] W. Xu, A. Li, Y. Liu, R. Chen, and W. Li, "CuMoO ${ }_{4}$ hexagonal boron nitride hybrid: an ecofriendly flame retardant for polyurethane elastomer," Journal of Material Science, vol. 53, no. 16, pp. 11265-11279, 2018.

[126] J. Wang, Y. Wu, Y. Xue et al., "Super-compatible functional boron nitride nanosheets/polymer films with excellent mechanical properties and ultra-high thermal conductivity for thermal management," Journal of Materials Chemistry C, vol. 6, no. 6, pp. 1363-1369, 2018.

[127] D. Wang, X. Mu, W. Cai, L. Song, C. Ma, and Y. Hu, "Constructing phosphorus, nitrogen, silicon-co-contained boron nitride nanosheets to reinforce flame retardant properties of unsaturated polyester resin," Composites Part A: Applied Science and Manufacturing, vol. 109, pp. 546-554, 2018.

[128] Z. Li, S. I. Montero Lira, L. Zhang, D. F. Expósito, V. B. Heeralal, and D. Wang, "Bio-inspired engineering of boron nitride with iron-derived nanocatalyst toward enhanced fire retardancy of epoxy resin," Polymer Degradation and Stability, vol. 157, pp. 119-130, 2018.

[129] L. Wang, L. Zhang, A. Fischer, Y. Zhong, D. Drummer, and $\mathrm{W}$. Wu, "Enhanced thermal conductivity and flame retardancy of polyamide 6/flame retardant composites with hexagonal boron nitride," Journal of Polymer Engineering, vol. 38, no. 8, pp. 767-774, 2018.

[130] Q. Zhang, Z. Li, X. Li, L. Yu, and Z. Wu, "Boron nitride nanosheets decorated by bismuth ferrite particles: preparation, characterization, and effect on flame-retardant performance of epoxy resin," Materials Research Express, vol. 5, no. 9, p. 95019, 2018.

[131] W. Cai, X. Mu, Y. Pan et al., "Facile fabrication of organically modified boron nitride nanosheets and its effect on the thermal stability, flame retardant, and mechanical properties of thermoplastic polyurethane," Polymers for Advanced Technologies, vol. 29, no. 9, pp. 2545-2552, 2018.

[132] S. Chen, R. Xu, J. Liu et al., "Simultaneous production and functionalization of boron nitride nanosheets by sugarassisted mechanochemical exfoliation," Advanced Materials, vol. 31, no. 10, Article ID 1804810, 2019.

[133] Q. Zhang, Z. Li, X. Li, L. Yu, Z. Zhang, and Z. Wu, "Zinc ferrite nanoparticle decorated boron nitride nanosheet: preparation, magnetic field arrangement, and flame retardancy," Chemical Engineering Journal, vol. 356, pp. 680-692, 2019.

[134] Y. Han, T. Li, B. Gao et al., "Synergistic effects of zinc oxide in montmorillonite flame-retardant polystyrene nanocomposites," Journal of Applied Polymer Science, vol. 133, p. 43047, 2016.

[135] D. Gao, R. Li, B. Lv, J. Ma, F. Tian, and J. Zhang, "Flammability, thermal and physical-mechanical properties of cationic polymer/montmorillonite composite on cotton fabric," Composites Part B: Engineering, vol. 77, pp. 329-337, 2015.

[136] F. Carosio, J. Kochumalayil, F. Cuttica, G. Camino, and L. Berglund, "Oriented clay nanopaper from biobased components-mechanisms for superior fire protection properties," A. C. S. Applied Materials \& Interfaces, vol. 7, no. 10, pp. 5847-5856, 2015.

[137] P. Ming, Z. Song, S. Gong et al., "Nacre-inspired integrated nanocomposites with fire retardant properties by graphene oxide and montmorillonite," Journal of Materials Chemistry A, vol. 3, no. 42, pp. 21194-21200, 2015.

[138] K. Shang, W. Liao, J. Wang, Y. Wang, Y. Wang, and D. A. Schiraldi, "Nonflammable alginate nanocomposite aerogels prepared by a simple freeze-drying and post-crosslinking method," A. C. S. Applied Materials \& Interfaces, vol. 8, no. 1, pp. 643-650, 2016.

[139] I. S. Zope, A. Dasari, F. Guan, and Z. Yu, "Influence of metal ions on thermo-oxidative stability and combustion response of polyamide 6/clay nanocomposites," Polymer, vol. 92, pp. 102$113,2016$.

[140] P. Scarfato, L. Incarnato, L. Di Maio, B. Dittrich, and B. Schartel, "Influence of a novel organo-silylated clay on the morphology, thermal and burning behavior of low density polyethylene composites," Composites Part B: Engineering, vol. 98, pp. 444-452, 2016.

[141] L. Zuo, W. Fan, Y. Zhang et al., "Graphene/montmorillonite hybrid synergistically reinforced polyimide composite aerogels with enhanced flame-retardant performance," Composites Science and Technology, vol. 139, pp. 57-63, 2017.

[142] S. Tang, V. Wachtendorf, P. Klack, L. Qian, Y. Dong, and B. Schartel, "Enhanced flame-retardant effect of a montmorillonite/phosphaphenanthrene compound in an epoxy thermoset," RSC Advances, vol. 7, no. 2, pp. 72-728, 2017. 
[143] Q. Kong, T. Wu, H. Zhang et al., "Improving flame retardancy of IFR/PP composites through the synergistic effect of organic montmorillonite intercalation cobalt hydroxides modified by acidified chitosan," Applied Clay Science, vol. 146, pp. 230-237, 2017.

[144] G. Makhlouf, M. Hassan, M. Nour, Y. K. Abdel-Monem, and A. Abdelkhalik, "Evaluation of fire performance of linear low-density polyethylene containing novel intumescent flame retardant," Journal of Thermal Analysis and Calorimetry, vol. 130, no. 2, pp. 1031-1041, 2017.

[145] Q. Fu, L. Medina, Y. Li, F. Carosio, A. Hajian, and L. A. Berglund, "Nanostructured wood hybrids for fireretardancy prepared by clay impregnation into the cell wall," $A$. C. S. Applied Materials \& Interfaces, vol. 9, no. 41, pp. 3615436163, 2017.

[146] S. Li, Z. Yang, J. Xu, J. Xie, and J. Sun, "Synthesis of exfoliated graphene-montmorillonite hybrids as the fillers for epoxy composites," Journal of Composite Materials, vol. 53, no. 3, pp. 315-326, 2018.

[147] F. Carosio, A. Di Pierro, J. Alongi, A. Fina, and G. Saracco, "Controlling the melt dripping of polyester fabrics by tuning the ionic strength of polyhedral oligomeric silsesquioxane and sodium montmorillonite coatings assembled through layer by layer," Journal of Colloid and Interface Science, vol. 510, pp. 142-151, 2018.

[148] L. Yan, Z. Xu, and X. Wang, "Synergistic effects of organically modified montmorillonite on the flame-retardant and smoke suppression properties of transparent intumescent fireretardant coatings," Progress in Organic Coatings, vol. 122, pp. 107-118, 2018.

[149] L. Jia, W. Zhang, B. Tong, and R. Yang, "Crystallization, flameretardant, and mechanical behaviors of poly(lactic acid) $\backslash 9,10$ dihydro-9-oxa-10-phosphaphenanthrene-10-oxide-calcium montmorillonite nanocomposite," Journal of Applied Polymer Science, vol. 136, no. 3, p. 46982, 2019.

[150] P. Chen, Y. Zhao, W. Wang, T. Zhang, and S. Song, "Correlation of montmorillonite sheet thickness and flame retardant behavior of a chitosan-montmorillonite nanosheet membrane assembled on flexible polyurethane foam," Polymers-Basel, vol. 11, no. 2, p. 213, 2019.

[151] H. Xie, X. Lai, Y. Wang, H. Li, and X. Zeng, "A green approach to fabricating nacre-inspired nanocoating for super-efficiently fire-safe polymers via one-step self-assembly," Journal of Hazardous Materials, vol. 365, pp. 125-136, 2019.

[152] J. Li, X. Li, Q. Wei et al., "Synergistic effect of organophosphate functionalized montmorillonite on properties and water resistance of intumescent flame-retarded SEBS," Fire and Materials, vol. 43, no. 1, pp. 74-83, 2019.

[153] K. Bocz, M. Domonkos, T. Igricz, Á. Kmetty, T. Bárány, and G. Marosi, "Flame retarded self-reinforced poly(lactic acid) composites of outstanding impact resistance," Composites Part A: Applied Science and Manufacturing, vol. 70, pp. 27-34, 2015.

[154] W. Xu, G. Wang, and X. Zheng, "Research on highly flameretardant rigid $\mathrm{PU}$ foams by combination of nanostructured additives and phosphorus flame retardants," Polymer Degradation and Stability, vol. 111, pp. 142-150, 2015.

[155] Y. Ren, Y. Wang, L. Wang, and T. Liu, "Evaluation of intumescent fire retardants and synergistic agents for use in wood flour/recycled polypropylene composites," Construction and Building Materials, vol. 76, pp. 273-278, 2015.
[156] Y. Wang, S. Liao, K. Shang et al., "Efficient approach to improving the flame retardancy of poly(vinyl alcohol)/clay aerogels: incorporating piperazine-modified ammonium polyphosphate," A. C. S. Applied Materials \& Interfaces, vol. 7, no. 3, pp. 1780-1786, 2015.

[157] L. Ye, J. Ren, S. Cai, Z. Wang, and J. Li, "Poly(lactic acid) nanocomposites with improved flame retardancy and impact strength by combining of phosphinates and organoclay," Chinese Journal of Polymer Science, vol. 34, no. 6, pp. 785-796, 2016.

[158] S. Deng, W. Liao, J. Yang, Z. Cao, and Y. Wang, "Flameretardant and smoke-suppressed silicone foams with chitosanbased nanocoatings," Industrial \& Engineering Chemistry Research, vol. 55, no. 27, pp. 7239-7248, 2016.

[159] M. Hassan, M. Nour, Y. Abdelmonem, G. Makhlouf, and A. Abdelkhalik, "Synergistic effect of chitosan-based flame retardant and modified clay on the flammability properties of LLDPE," Polymer Degradation and Stability, vol. 133, pp. 8-15, 2016.

[160] O. Köklükaya, F. Carosio, and L. Wågberg, "Superior flameresistant cellulose nanofibril aerogels modified with hybrid layer-by-layer coatings," A. C. S. Applied Materials \& Interfaces, vol. 9, no. 24, pp. 29082-29092, 2017.

[161] D. Vadas, T. Igricz, J. Sarazin, S. Bourbigot, G. Marosi, and K. Bocz, "Flame retardancy of microcellular poly(lactic acid) foams prepared by supercritical $\mathrm{CO}_{2}$-assisted extrusion," Polymer Degradation and Stability, vol. 153, pp. 100-108, 2018.

[162] M. Jiang, Y. Zhang, Y. Yu et al., "Flame retardancy of unsaturated polyester composites with modified ammonium polyphosphate, montmorillonite, and zinc borate," Journal of Applied Polymer Science, vol. 136, no. 11, p. 47180, 2019.

[163] D. Zhang, B. L. Williams, E. M. Becher et al., "Flame retardant and hydrophobic cotton fabrics from intumescent coatings," Advanced Composites and Hybrid Materials, vol. 1, no. 1, pp. 177-184, 2018.

[164] M. Tomczak, J. Łopiński, K. Kowalczyk, B. Schmidt, and J. Rokicka, "Vinyl intumescent coatings modified with platelet-type nanofillers," Progress in Organic Coatings, vol. 126, pp. 97-105, 2019.

[165] F. Ronkay, B. Molnár, F. Szalay et al., "Development of flameretarded nanocomposites from recycled pet bottles for the electronics industry," Polymers-Basel, vol. 11, no. 2, p. 233, 2019.

[166] Y. Li, C. Deng, X. Shi, B. Xu, H. Chen, and Y. Wang, "Simultaneously improved flame retardance and ceramifiable properties of polymer-based composites via the formed crystalline phase at high temperature," A. C. S. Applied Materials \& Interfaces, vol. 11, no. 7, pp. 7459-7471, 2019.

[167] S. Zhang, Y. Yan, W. Wang et al., "Intercalation of phosphotungstic acid into layered double hydroxides by reconstruction method and its application in intumescent flame retardant poly (lactic acid) composites," Polymer Degradation and Stability, vol. 147, pp. 142-150, 2018.

[168] C. Li, J. Wan, E. N. Kalali, H. Fan, and D. Wang, "Synthesis and characterization of functional eugenol derivative based layered double hydroxide and its use as a nanoflame-retardant in epoxy resin," Journal of Materials Chemistry A, vol. 3, no. 7, pp. 3471-3479, 2015.

[169] P. Ding, B. Kang, J. Zhang et al., "Phosphorus-containing flame retardant modified layered double hydroxides and their applications on polylactide film with good transparency," 
Journal of Colloid and Interface Science, vol. 440, pp. 46-52, 2015.

[170] E. N. Kalali, S. De Juan, X. Wang, S. Nie, R. Wang, and D. Wang, "Comparative study on synergistic effect of LDH and zirconium phosphate with aluminum trihydroxide on flame retardancy of EVA composites," Journal of Thermal Analysis and Calorimetry, vol. 121, no. 2, pp. 619-626, 2015.

[171] Y. Qian, S. Zhou, and X. Chen, "Flammability and thermal degradation behavior of ethylene-vinyl acetate/layered double hydroxides/zinc borate composites," Polymers for Advanced Technologies, vol. 28, no. 3, pp. 353-361, 2017.

[172] Y. Shi, Z. Gui, B. Yu, R. K. K. Yuen, B. Wang, and Y. Hu, "Graphite-like carbon nitride and functionalized layered double hydroxide filled polypropylene-grafted maleic anhydride nanocomposites: comparison in flame retardancy, and thermal, mechanical and UV-shielding properties," Composites Part B: Engineering, vol. 79, pp. 277-284, 2015.

[173] K. Shang, W. Liao, J. Wang, Y. Wang, Y. Wang, and D. A. Schiraldi, "Nonflammable alginate nanocomposite aerogels prepared by a simple freeze-drying and post-crosslinking method," A. C. S. Applied Materials \& Interfaces, vol. 8, no. 1, pp. 643-650, 2016.

[174] K. Zhou, Z. Gui, and Y. Hu, "Facile synthesis of LDH nanoplates as reinforcing agents in PVA nanocomposites," Polymers for Advanced Technologies, vol. 28, no. 3, pp. 386-392, 2017.

[175] S. Gómez-Fernández, M. Günther, B. Schartel, M. A. Corcuera, and A. Eceiza, "Impact of the combined use of layered double hydroxides, lignin and phosphorous polyol on the fire behavior of flexible polyurethane foams," Industrial Crops and Products, vol. 125, pp. 346-359, 2018.

[176] H. Wang, S. Tan, and R. Song, "Effect of trace chloride on the char formation and flame retardancy of the LLDPE filled with NiAl-layered double hydroxides," Fire and Materials, vol. 43, no. 1, pp. 110-120, 2019.

[177] K. Zhu, Y. Wang, D. Tang et al., "Flame-retardant mechanism of layered double hydroxides in asphalt binder," Materials, vol. 12 , no. 5 , p. $801,2019$.

[178] M. Hajibeygi, M. Shabanian, and H. A. Khonakdar, “Zn-AL $\mathrm{LDH}$ reinforced nanocomposites based on new polyamide containing imide group: From synthesis to properties," Applied Clay Science, vol. 114, pp. 256-264, 2015.

[179] E. N. Kalali, X. Wang, and D. Wang, "Synthesis of a $\mathrm{Fe}^{3} \mathrm{O}^{4}$ nanosphere@Mg-Al layered-double-hydroxide hybrid and application in the fabrication of multifunctional epoxy nanocomposites," Industrial \& Engineering Chemistry Research, vol. 55, no. 23, pp. 6634-6642, 2016.

[180] E. N. Kalali, X. Wang, and D. Wang, "Multifunctional intercalation in layered double hydroxide: toward multifunctional nanohybrids for epoxy resin," Journal of Materials Chemistry A, vol. 4, no. 6, pp. 2147-2157, 2016.

[181] C. Li, J. Wan, Y. Pan, P. Zhao, H. Fan, and D. Wang, "Sustainable, biobased silicone with layered double hydroxide hybrid and their application in natural-fiber reinforced phenolic composites with enhanced performance," A. C. S. Sustain Chemistry \& Engineering, vol. 4, no. 6, pp. 3113-3121, 2016.

[182] J. Cai, H. Heng, X. Hu, Q. Xu, and F. Miao, "A facile method for the preparation of novel fire-retardant layered double hydroxide and its application as nanofiller in UP," Polymer Degradation and Stability, vol. 126, pp. 47-57, 2016.

[183] M. Kumar, S. Chakraborty, P. Upadhyaya, and G. Pugazhenthi, "Morphological, mechanical, and thermal features of PMMA nanocomposites containing two-dimensional Co-Al layered double hydroxide," Journal of Applied Polymer Science, vol. 135, no. 5, p. 45774, 2018.

[184] X. Jin, X. Gu, C. Chen et al., “The fire performance of polylactic acid containing a novel intumescent flame retardant and intercalated layered double hydroxides," Journal of Materials Science, vol. 52, no. 20, pp. 12235-12250, 2017.

[185] J. Du, L. Jin, H. Zeng et al., "Facile preparation of an efficient flame retardant and its application in ethylene vinyl acetate," Applied Clay Science, vol. 168, pp. 96-105, 2019.

[186] K. Zhou, Y. Hu, J. Liu, Z. Gui, S. Jiang, and G. Tang, "Facile preparation of layered double hydroxide $/ \mathrm{MoS}_{2} /$ poly(vinyl alcohol) composites," Materials Chemisty and Physics, vol. 178, pp. 1-5, 2016.

[187] A. Edenharter, P. Feicht, B. Diar-Bakerly, G. Beyer, and J. Breu, "Superior flame retardant by combining high aspect ratio layered double hydroxide and graphene oxide," Polymer, vol. 91, pp. 41-49, 2016.

[188] Y. Yan, H. Yao, L. Mao et al., "Micrometer-thick graphene oxide-layered double hydroxide nacre-inspired coatings and their properties," Small, vol. 12, no. 6, pp. 745-755, 2016.

[189] K. Zhou, R. Gao, and X. Qian, "Self-assembly of exfoliated molybdenum disulfide $\left(\mathrm{MoS}_{2}\right)$ nanosheets and layered double hydroxide (LDH): towards reducing fire hazards of epoxy," Journal of Hazardous Materials, vol. 338, pp. 343-355, 2017.

[190] B. Guo, Y. Liu, Q. Zhang et al., "Efficient flame-retardant and smoke-suppression properties of $\mathrm{Mg}$-Al-layered doublehydroxide nanostructures on wood substrate," A. C. S. Sustain Chemistry \& Engineering, vol. 9, no. 27, pp. 23039-23047, 2017.

[191] W. Xu, B. Zhang, X. Wang, G. Wang, and D. Ding, "The flame retardancy and smoke suppression effect of a hybrid containing $\mathrm{CuMoO}_{4}$ modified reduced graphene oxide/layered double hydroxide on epoxy resin," Journal of Hazardous Materials, vol. 343, pp. 364-375, 2018.

[192] Y. Hou, S. Qiu, Y. Hu, C. K. Kundu, Z. Gui, and W. Hu, "Construction of bimetallic ZIF-derived $\mathrm{Co}-\mathrm{Ni}$ ldhs on the surfaces of go or cnts with a recyclable method: toward reduced toxicity of gaseous thermal decomposition products of unsaturated polyester resin," ACS Applied Materials \& Interfaces, vol. 10, no. 21, pp. 18359-18371, 2018.

[193] Z. Li, J. Zhang, F. Dufossea, and D. Wang, "Ultrafine nickel nanocatalyst-engineering of an organic layered double hydroxide towards a super-efficient fire-safe epoxy resin via interfacial catalysis," Journal of Materials Chemistry A, vol. 6, no. 18, pp. 8488-8498, 2018.

[194] S. Xu, M. Zhang, S. Li et al., "Surface modification of phosphorus-containing hydrotalcite using rare-earth coupling agent and its application in polypropylene," Powder Technology, vol. 342, pp. 555-561, 2019.

[195] F. Carosio, L. Maddalena, J. Gomez, G. Saracco, and A. Fina, "Graphene oxide exoskeleton to produce self-extinguishing, nonignitable, and flame resistant flexible foams: a mechanically tough alternative to inorganic aerogels," Advanced Materials and Interfaces, vol. 5, no. 23, Article ID 1801288, 2018.

[196] B. Wicklein, A. Kocjan, G. Salazar-Alvarez et al., "Thermally insulating and fire-retardant lightweight anisotropic foams based on nanocellulose and graphene oxide," Nature Nanotechnology, vol. 10, no. 3, pp. 277-283, 2015.

[197] C. Hu, J. Xue, L. Dong et al., "Scalable preparation of multifunctional fire-retardant ultralight graphene foams," ACS Nano, vol. 10, no. 1, pp. 1325-1332, 2016. 
[198] L. Zhang, H. Li, X. Lai, X. Su, T. Liang, and X. Zeng, “Thiolated graphene-based superhydrophobic sponges for oil-water separation," Chemical Engineering Journal, vol. 316, pp. 736743, 2017.

[199] Y. Yan, H. Yao, L. Mao et al., "Micrometer-thick graphene oxide-layered double hydroxide nacre-inspired coatings and their properties," Small, vol. 12, no. 6, pp. 745-755, 2016.

[200] L. Dong, C. Hu, L. Song, X. Huang, N. Chen, and L. Qu, "A large-area, flexible, and flame-retardant graphene paper," Advanced Functional Materials, vol. 26, no. 9, pp. 1470-1476, 2016.

[201] B. Yuan, H. Sheng, X. Mu et al., "Enhanced flame retardancy of polypropylene by melamine-modified graphene oxide," Journal of Materials Science, vol. 50, no. 16, pp. 5389-5401, 2015.

[202] B. Yu, Y. Shi, B. Yuan et al., "Enhanced thermal and flame retardant properties of flame-retardant-wrapped graphene/ epoxy resin nanocomposites," Journal of Materials Chemistry $A$, vol. 3, no. 15, pp. 8034-8044, 2015.

[203] J. Gu, C. Liang, X. Zhao et al., "Highly thermally conductive flame-retardant epoxy nanocomposites with reduced ignitability and excellent electrical conductivities," Composites Science and Technology, vol. 139, pp. 83-89, 2017.

[204] B. Yuan, A. Fan, M. Yang et al., "The effects of graphene on the flammability and fire behavior of intumescent flame retardant polypropylene composites at different flame scenarios," Polymers Degradation Stability, vol. 143, pp. 42-56, 2017.

[205] W. Cai, X. Feng, B. Wang et al., "A novel strategy to simultaneously electrochemically prepare and functionalize graphene with a multifunctional flame retardant," Chemical Engineering Journal, vol. 316, pp. 514-524, 2017.

[206] W. Yan, M. Zhang, J. Yu, S. Nie, D. Zhang, and S. Qin, "Synergistic flame-retardant effect of epoxy resin combined with phenethyl-bridged DOPO derivative and graphene nanosheets," Chinese Journal of Polymer Science, vol. 37, no. 1, pp. 79-88, 2019.

[207] B. Yuan, Y. Sun, X. Chen, Y. Shi, H. Dai, and S. He, "Dual modification of graphene by polymeric flame retardant and $\mathrm{Ni}(\mathrm{OH})_{2}$ nanosheets for improving flame retardancy of polypropylene," Composites Part A: Applied Science and Manufacturing, vol. 109, pp. 345-354, 2018.

[208] B. Wu, Y. Liu, Y. Shu, L. Ye, and X. Zhao, "Intrinsic flameretardant urea formaldehyde/graphene nanocomposite foam: structure and reinforcing mechanism," Polymer Composites, vol. 40, no. S1, pp. E811-E820, 2019.

[209] W. Cai, J. Wang, X. Wang et al., "Mussel-inspired functionalization of electrochemically exfoliated graphene: based on self-polymerization of dopamine and its suppression effect on the fire hazards and smoke toxicity of thermoplastic polyurethane," Journal of Hazardous Materials, vol. 352, pp. 57-69, 2018.

[210] J. Long, S. Li, J. Liang, Z. Wang, and B. Liang, "Preparation and characterization of graphene oxide and it application as a reinforcement in polypropylene composites," Polymer Composites, vol. 40, no. 2, pp. 723-729, 2019.

[211] G. Yuan, B. Yang, Y. Chen, and Y. Jia, "Synthesis of a novel multi-structure synergistic POSS-GO-DOPO ternary graft flame retardant and its application in polypropylene," Composites Part A: Applied Science and Manufacturing, vol. 117, pp. 345-356, 2019.
[212] B. Yu, Y. Shi, B. Yuan et al., "Enhanced thermal and flame retardant properties of flame-retardant-wrapped graphene/ epoxy resin nanocomposites," Journal of Materials Chemistry $A$, vol. 3, no. 15, pp. 8034-8044, 2015.

[213] J. Jing, Y. Zhang, X. Tang, X. Li, M. Peng, and Z. Fang, "Combination of a bio-based polyphosphonate and modified graphene oxide toward superior flame retardant polylactic acid," RSC Advances, vol. 8, pp. 4304-4313, 2018.

[214] Y. Feng, C. He, Y. Wen et al., "Superior flame retardancy and smoke suppression of epoxy-based composites with phosphorus/nitrogen co-doped graphene," Journal of Hazardous Materials, vol. 346, pp. 140-151, 2018.

[215] D. A. Pethsangave, R. V. Khose, P. H. Wadekar, and S. Some, "Novel approach toward the synthesis of a phosphorusfunctionalized polymer-based graphene composite as an efficient flame retardant," A. C. S. Sustainable Chemistry \& Engineering, vol. 7, no. 13, pp. 11745-11753, 2019.

[216] M. Li, H. Zhang, W. Wu et al., "A novel POSS-based copolymer functionalized graphene: an effective flame retardant for reducing the flammability of epoxy resin," Polymers-Basel, vol. 11, no. 2, p. 241, 2019.

[217] K. Zhou, Z. Gui, Y. Hu, S. Jiang, and G. Tang, "The influence of cobalt oxide-graphene hybrids on thermal degradation, fire hazards and mechanical properties of thermoplastic polyurethane composites," Composites Part A: Applied Science and Manufacturing, vol. 88, pp. 10-18, 2016.

[218] S. Wang, R. Gao, and K. Zhou, "The influence of cerium dioxide functionalized reduced graphene oxide on reducing fire hazards of thermoplastic polyurethane nanocomposites," Journal of Colloid and Interface Science, vol. 536, pp. 127-134, 2019.

[219] H. Sheng, Y. Zhang, C. Ma et al., "Influence of zinc stannate and graphene hybrids on reducing the toxic gases and fire hazards during epoxy resin combustion," Polymers Advanced Technologies, vol. 30, no. 3, pp. 666-674, 2019.

[220] B. Yuan, Y. Hu, X. Chen et al., "Dual modification of graphene by polymeric flame retardant and $\mathrm{Ni}(\mathrm{OH})_{2}$ nanosheets for improving flame retardancy of polypropylene," Composites Part A: Applied Science and Manufacturing, vol. 100, pp. 106117, 2017.

[221] L. Wang, J. Wang, L. Zheng, Z. Li, L. Wu, and X. Wang, "Superelastic, anticorrosive, and flame-resistant nitrogencontaining resorcinol formaldehyde/graphene oxide composite aerogels," A. C. S. Sustainable Chemistry \& Engineering, vol. 7, no. 12, pp. 10873-10879, 2019.

[222] F. L. Guan, C. X. Gui, H. B. Zhang, Z. G. Jiang, Y. Jiang, and Z. Z. Yu, "Enhanced thermal conductivity and satisfactory flame retardancy of epoxy/alumina composites by combination with graphene nanoplatelets and magnesium hydroxide," Composites Part B: Engineering, vol. 98, pp. 134-140, 2016.

[223] W. Xu, X. Wang, Y. Wu, W. Li, and C. Chen, "Functionalized graphene with Co-ZIF adsorbed borate ions as an effective flame retardant and smoke suppression agent for epoxy resin," Journal of Hazardous Materials, vol. 363, pp. 138-151, 2019.

[224] W. Xu, X. Wang, G. Wang, A. Li, and B. Xu, "A novel graphene hybrid for reducing fire hazard of epoxy resin," Polymers Advanced Technologies, vol. 29, no. 4, pp. 1194-1205, 2018.

[225] P. Ming, Z. Song, S. Gong et al., "Nacre-inspired integrated nanocomposites with fire retardant properties by graphene oxide and montmorillonite," Journals of Materials Chemistry A, vol. 3, no. 42, pp. 21194-21200, 2015. 
[226] F.-F. Chen, Y.-J. Zhu, F. Chen, L.-Y. Dong, R.-L. Yang, and Z.-C. Xiong, "Fire alarm wallpaper based on fire-resistant hydroxyapatite nanowire inorganic paper and graphene oxide thermosensitive sensor," ACS Nano, vol. 12, no. 4, pp. 3159$3171,2018$.

[227] L. Zuo, W. Fan, Y. Zhang et al., "Graphene/montmorillonite hybrid synergistically reinforced polyimide composite aerogels with enhanced flame-retardant performance," Composites Science and Technology, vol. 139, pp. 57-63, 2017.

[228] Y. Guo, Y. Xue, X. Zuo et al., "Capitalizing on the molybdenum disulfide/graphene synergy to produce mechanical enhanced flame retardant ethylene-vinyl acetate composites with low aluminum hydroxide loading," Polymer Degradation and Stability, vol. 144, pp. 155-166, 2017.

[229] W. Lin, W. Hong, L. Sun, D. Yu, D. Yu, and X. Chen, "Bioinspired mesoporous chiral nematic graphitic carbon nitride photocatalysts modulated by polarized light," ChemSusChem., vol. 11, no. 1, pp. 114-119, 2018.

[230] L. Sun, M. Yang, J. Huang, D. Yu, W. Hong, and X. Chen, "Freestanding graphitic carbon nitride photonic crystals for enhanced photocatalysis," Advanced Functional Materials, vol. 26, no. 27, pp. 4943-4950, 2016.

[231] Y. Q. Shi, Z. Gui, B. Yu, R. K. K. Yuen, B. Wang, and Y. $\mathrm{Hu}$, "Graphite-like carbon nitride and functionalized layered double hydroxide filled polypropylene-grafted maleic anhydride nanocomposites: Comparison in flame retardancy, and thermal, mechanical and UV-shielding properties," Journal/Composites Part B: Engineering, vol. 79, pp. 277-284, 2015.

[232] Y. Q. Shi, W. Y. Xing, B. B. Wang et al., "Synergistic effect of graphitic carbon nitride and ammonium polyphosphate for enhanced thermal and flame retardant properties of polystyrene," Materials Chemistry and Physics, vol. 177, pp. 283-292, 2016.

[233] Y. Zhu, Y. Shi, Z. Huang, L. Duan, Q. Tai, and Y. Hu, "Novel graphite-like carbon nitride/organic aluminum diethylhypophosphites nanohybrid: preparation and enhancement on thermal stability and flame retardancy of polystyrene," Composites Part A: Applied Science and Manufacturing, vol. 99, pp. 149-156, 2017.

[234] Y. Shi, B. Yu, K. Zhou et al., "Novel $\mathrm{CuCo}_{2} \mathrm{O}_{4} /$ graphitic carbon nitride nanohybrids: Highly effective catalysts for reducing CO generation and fire hazards of thermoplastic polyurethane nanocomposites," Journal of Hazardous Materials, vol. 293, pp. 87-96, 2015.

[235] Y. Shi, B. Yu, L. Duan et al., "Graphitic carbon nitride/ phosphorus-rich aluminum phosphinates hybrids as smoke suppressants and flame retardants for polystyrene," Journal of Hazardous Materials, vol. 332, pp. 87-96, 2017.

[236] Y. Shi, L. Wang, L. Fu et al., "Sodium alginate-templated synthesis of g- $\mathrm{C}_{3} \mathrm{~N}_{4}$ /carbon spheres/Cu ternary nanohybrids for fire safety application," Journal of Colloid and Interface Science, vol. 539, pp. 1-10, 2019.

[237] Y. Hou, W. Hu, Z. Gui, and Y. Hu, "Preparation of metalorganic frameworks and their application as flame retardants for polystyrene," Industrial \& Engineering Chemistry Research, vol. 56, no. 8, pp. 2036-2045, 2017.

[238] Y. Hou, L. Liu, S. Qiu, X. Zhou, Z. Gui, and Y. Hu, “DOPOmodified two-dimensional Co-based metal-organic framework: preparation and application for enhancing fire safety of poly(lactic acid)," A. C. S. Applied Materials \& Interfaces, vol. 10, no. 9, pp. 8274-8286, 2018.

[239] X. Mu, J. Zhan, C. Ma et al., "Integrated effect of flame retardant wrapped macromolecular covalent organic nanosheet on reduction of fire hazards of epoxy resin," Composites Part A: Applied Science and Manufacturing, vol. 117, pp. 23-33, 2019. 


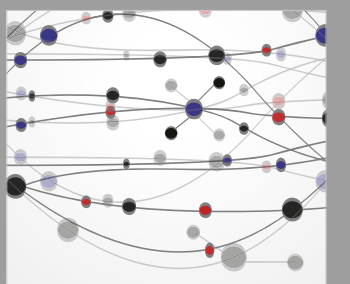

The Scientific World Journal
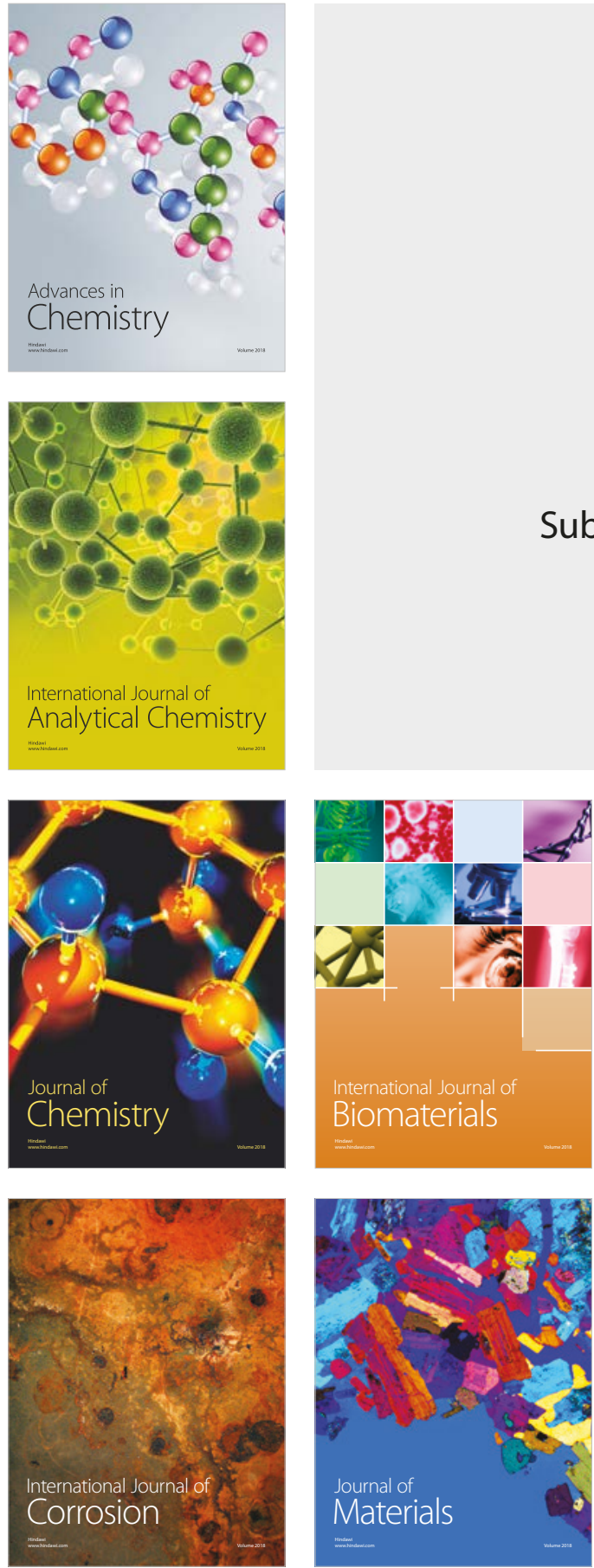

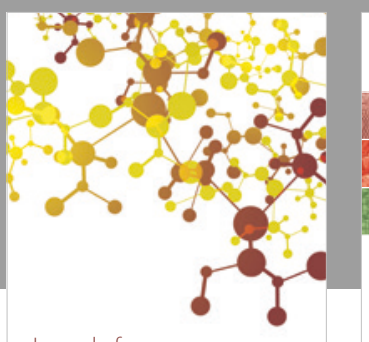

Journal of

Applied Chemistry
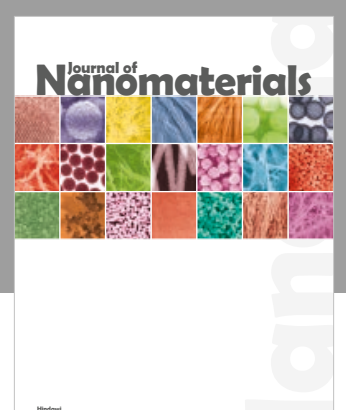

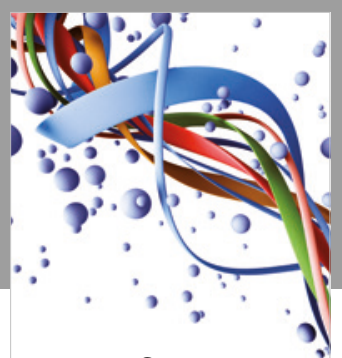

Scientifica

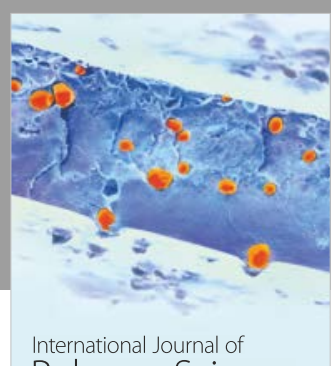

Polymer Science

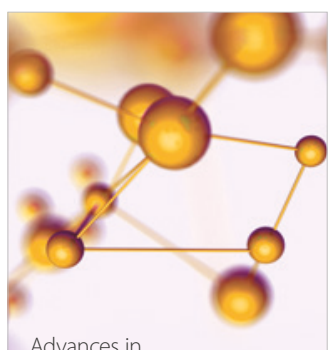

Physical Chemistry
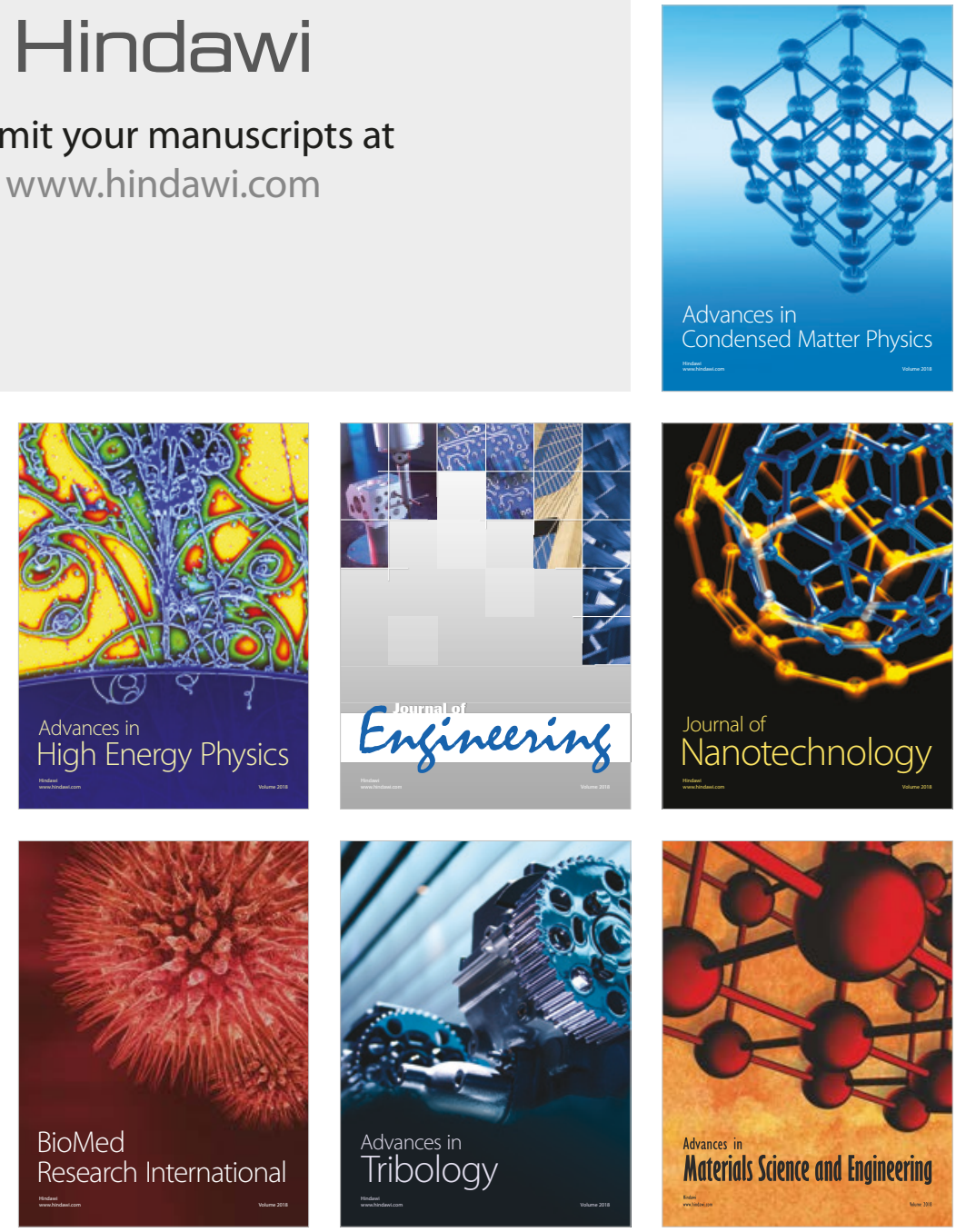